\title{
Vaporized Cannabis Extracts Have Reinforcing Properties and Support Conditioned Drug-Seeking Behavior in Rats
}

\author{
Timothy G. Freels, ${ }^{1}$ Lydia N. Baxter-Potter, ${ }^{1}$ Janelle M. Lugo, ${ }^{1}{ }^{\circledR}$ Nicholas C. Glodosky, ${ }^{2}$ Hayden R. Wright, ${ }^{1}$

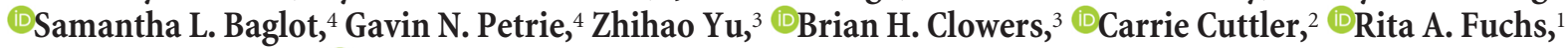 \\ Matthew N. Hill, ${ }^{4}$ and $\odot$ Ryan J. McLaughlin ${ }^{1,2}$ \\ Departments of ${ }^{1}$ Integrative Physiology and Neuroscience, ${ }^{2}$ Psychology, ${ }^{3}$ Chemistry, Washington State University, Pullman, Washington 99164 , and \\ ${ }^{4}$ Departments of Cell Biology and Anatomy and Psychiatry, Hotchkiss Brain Institute, University of Calgary, Calgary, Alberta T2N 4N1, Canada
}

Recent trends in cannabis legalization have increased the necessity to better understand the effects of cannabis use. Animal models involving traditional cannabinoid self-administration approaches have been notoriously difficult to establish and differences in the drug used and its route of administration have limited the translational value of preclinical studies. To address this challenge in the field, we have developed a novel method of cannabis self-administration using response-contingent delivery of vaporized $\Delta^{9}$-tetrahydrocannabinol-rich $\left(\mathrm{CAN}_{\mathrm{THC}}\right)$ or cannabidiol-rich $\left(\mathrm{CAN}_{\mathrm{CBD}}\right)$ whole-plant cannabis extracts. Male Sprague-Dawley rats were trained to nose-poke for discrete puffs of $\mathrm{CAN}_{\mathrm{THC}}, \mathrm{CAN}_{\mathrm{CBD}}$, or vehicle (VEH) in daily $1 \mathrm{~h}$ sessions. Cannabis vapor reinforcement resulted in strong discrimination between active and inactive operanda. $\mathrm{CAN}_{\mathrm{THC}}$ maintained higher response rates under fixed ratio schedules and higher break points under progressive ratio schedules compared with $\mathrm{CAN}_{\mathrm{CBD}}$ or VEH, and the number of vapor deliveries positively correlated with plasma THC concentrations. Moreover, metabolic phenotyping studies revealed alterations in locomotor activity, energy expenditure, and daily food intake that are consistent with effects in human cannabis users. Furthermore, both cannabis regimens produced ecologically relevant brain concentrations of THC and CBD and CAN ${ }_{\mathrm{THC}}$ administration decreased hippocampal CB1 receptor binding. Removal of $\mathrm{CAN}_{\mathrm{THC}}$ reinforcement (but not $\mathrm{CAN}_{\mathrm{CBD}}$ ) resulted in a robust extinction burst and an increase in cue-induced cannabis-seeking behavior relative to VEH. These data indicate that volitional exposure to THC-rich cannabis vapor has bona fide reinforcing properties and collectively support the utility of the vapor self-administration model for the preclinical assessment of volitional cannabis intake and cannabis-seeking behaviors.

Key words: cannabinoid; cannabis; rat; self-administration; translational; vapor

Significance Statement

The evolving legal landscape concerning recreational cannabis use has increased urgency to better understand its effects on the brain and behavior. Animal models are advantageous in this respect; however, current approaches typically used forced injections of synthetic cannabinoids or isolated cannabis constituents that may not capture the complex effects of volitional cannabis consumption. We have developed a novel model of cannabis self-administration using response-contingent delivery of vaporized cannabis extracts containing high concentrations of $\Delta^{9}$ tetrahydrocannabinol (THC) or cannabidiol. Our data indicate that THC-rich cannabis vapor has reinforcing properties that support stable rates of responding and conditioned drug-seeking behavior. This approach will be valuable for interrogating effects of cannabis and delineating neural mechanisms that give rise to aberrant cannabis-seeking behavior.

\section{Introduction}

With several states recently passing legislation allowing for the use of cannabis for recreational purposes, there is a pressing need

This work was supported by NIH NIDA Grants R21 DA043722-01A1 (R.J.M.) and R01 DA025646-07 (R.A.F.), by a to better understand the effects of cannabis use/misuse. Animal models are valuable in this regard because they afford precise control over extraneous variables that complicate interpretation of cross-sectional human data. However, current approaches 
have limited translational value (McLaughlin, 2018). Synthetic cannabinoid receptor 1 (CB1R) agonists or isolated cannabis constituents [e.g., $\Delta^{9}$-tetrahydrocannabinol(THC), cannabidiol (CBD)] have become the drug of choice in rodent models of cannabis exposure; even though the pharmacological properties of these compounds differ greatly from those of inhaled cannabis. THC and synthetic CB1R agonists have different pharmacological profiles (partial vs full agonists) and recruit different intracellular signaling pathways (Laprairie et al., 2014). Thus, synthetic CB1R agonists may fail to recapitulate the effects of THC, let alone the effects of cannabis.

Animal models involving access to THC alone have drawbacks as well. Over 120 unique phytocannabinoids are present in Cannabis sativa in addition to THC. Proportions of phytocannabinoids can vary considerably across cannabis chemovars and their distinct pharmacological profiles and potential to interact may give rise to their unique psychotropic effects (Fisar, 2009; Russo, 2011; Hill et al., 2012; Lewis et al., 2018). For example, $\mathrm{CBD}$ is a CB1R negative allosteric modulator and inhibits THCdependent intracellular signaling and $\beta$-arrestin-2-mediated CB1R internalization (Laprairie et al., 2015, 2016). CBD attenuates THC-induced paranoia and memory impairments in humans (Englund et al., 2013) but can also increase THC serum concentrations when co-administered with THC (Greene et al., 2018). Therefore, THC administration alone may not produce effects that are representative of the effects of cannabis exposure in humans. Accordingly, THC self-administration has been difficult to demonstrate at the preclinical level (Tanda, 2016). Rats acquire stable rates of intravenous THC-CBD (10:1) selfadministration only after extended passive pre-exposure to vaporized THC-CBD (Spencer et al., 2018). Thus, studying the effects of THC in the presence of other phytocannabinoids is important for modeling cannabis use.

Current animal models typically use the intravenous route for drug delivery, even though the most common route of cannabis use is inhalation (Sexton et al., 2016), and the pharmacokinetics of cannabinoids vary considerably depending on administration route (Grotenhermen, 2003; Huestis, 2007; Hložek et al., 2017). In humans, intravenous THC administration produces adverse effects often because of high dosing and fast infusion rates (Carbuto et al., 2012). Similarly, vaporized THC administration produces conditioned place preference, whereas intraperitoneal THC administration produces conditioned place avoidance in rodents (Manwell et al., 2014). Thus, both dose and route of administration may fundamentally influence the degree to which cannabis can support self-administration.

A more translationally relevant approach is needed that uses cannabis and mimics the most common route of administration in human users. With this in mind, we have developed a novel, ecologically valid model of cannabis vapor self-administration that uses "e-cigarette" technology to deliver discrete puffs of vaporized cannabis extracts to rodents in a response-contingent manner. We used this approach to examine whether vaporized cannabis extracts have reinforcing properties that support stable drug-taking behavior. We used whole-plant cannabis extracts predominantly containing THC or CBD, but also containing trace amounts of other phytocannabinoids often found in natural cannabis products. We characterized the metabolic phenotype of

The authors declare no competing financial interests.

Correspondence should be addressed to Ryan J.McLaughlin at ryan.mclaughlin@wsu.edu.

https://doi.org/10.1523/JNEUROSCI.2416-19.2020

Copyright $@ 2020$ the authors
Table 1. Assignment of animals and experimental parameters

\begin{tabular}{|c|c|c|c|c|c|}
\hline Procedure & $\operatorname{CAN}_{\text {THC }}(n)$ & $\operatorname{CAN}_{\mathrm{CBD}}(n)$ & $\operatorname{VEH}(n)$ & SA days & $\begin{array}{l}\text { Vapor } \\
\text { system }\end{array}$ \\
\hline$F R / P R$ & 11 & 12 & 7 & 22 & 2ndGEN \\
\hline Plasma CB & $400 \mathrm{mg} / \mathrm{ml}=8$ & $400 \mathrm{mg} / \mathrm{ml}=8$ & & $12-16$ & 1st GEN \\
\hline Quantification & $200 \mathrm{mg} / \mathrm{ml}=17$ & $200 \mathrm{mg} / \mathrm{ml}=17$ & & $12-16$ & 1st GEN \\
\hline Brain CB quantification & 11 & 11 & & 19 & 2nd GEN \\
\hline CB1R binding & 4 & 4 & 4 & 22 & 2nd GEN \\
\hline Radio telemetry & 3 & 3 & 2 & 19 & 1st GEN \\
\hline Metabolic phenotyping & 6 & 6 & 5 & 22 & 2nd GEN \\
\hline CB1R antagonism & 8 & 8 & & 27 & 1st GEN \\
\hline EPM & 13 & 13 & 11 & 19 & 1st GEN \\
\hline Extinction/reinstatement & 13 & 11 & 11 & 19 & 1st GEN \\
\hline
\end{tabular}

SA, self-administration; GEN, generation. Doses for $\mathrm{CAN}_{\mathrm{THC}}$ and $C \mathrm{CN}_{\mathrm{CBD}}$ are $400 \mathrm{mg} / \mathrm{ml}$ unless otherwise specified. Studies involving $F R / P R$ responding, brain CB quantification, CB1R binding, and metabolic phenotyping were conducted in the same cohort of rats. Studies involving radio telemetry, EPM testing, and extinction/reinstatement were conducted in the same cohort of rats. Studies involving plasma CB quantification and CB1R antagonism were each conducted in independent cohorts of rats that were not used for any other experiments.

cannabis-trained rats and because human cannabis users and rodents treated with THC exhibit reduced CB1R availability (Ceccarini et al., 2015) and decreased CB1R expression/binding, particularly within the hippocampus (Romero et al., 1997; Silva et al., 2015; Farquhar et al., 2019; Kruse et al., 2019), we also measured hippocampal CB1 receptor binding $24 \mathrm{~h}$ after vapor self-administration. Given that acute abstinence can unmask withdrawal-related affective symptoms for other drugs (Hasin et al., 2008), we examined whether acute forced abstinence from cannabis vapor increases anxiety-like behavior. Finally, we tested whether vaporized cannabis maintains drug seeking in the drugpredictive context (i.e., under extinction conditions) or upon response-contingent presentation of a cannabis-paired light stimulus (i.e., cue-induced reinstatement).

\section{Materials and Methods}

Animals. Male Sprague-Dawley rats (Simonsen Laboratories; 350-400 g) were pair-housed in a humidity-controlled vivarium on a $12 \mathrm{~h}$ reverse light/dark schedule (lights off at 07:00). Food and water were available ad libitum. All procedures followed the National Institutes of Health Guide for the Care and Use of Laboratory Animals and were approved by the Washington State University Institutional Animal Care and Use Committee. Table 1 describes the assignment of animals to various experiments, sample sizes, and relevant experimental parameters.

Drugs. Cannabis extracts containing high concentrations of THC $\left(\mathrm{CAN}_{\mathrm{THC}}\right)$ or $\mathrm{CBD}\left(\mathrm{CAN}_{\mathrm{CBD}}\right)$ were obtained from the National Institute on Drug Abuse (NIDA) Drug Supply Program. According to the certificate of analyses provided upon shipment, the $\mathrm{CAN}_{\mathrm{THC}}$ extract contained $28.4 \%$ THC, $1.38 \% \mathrm{CBD}$, and $1.8 \%$ cannabinol $(\mathrm{CBN})$. The $\mathrm{CAN}_{\mathrm{CBD}}$ extract contained $1.16 \%$ THC, $59.34 \%$ CBD, $2.1 \%$ cannabichromene (CBC), $1.1 \%$ cannabigerol (CBG), and $<0.01 \%$ tetrahydrocannabivarin and $\mathrm{CBN}$. Extracts were heated to $60^{\circ} \mathrm{C}$ under constant stirring and dissolved in $80 \%$ propylene glycol $/ 20 \%$ vegetable glycerol vehicle (VEH) at a concentration of 200 or $400 \mathrm{mg} / \mathrm{ml}$ based on previous studies (Nguyen et al., 2016; Javadi-Paydar et al., 2018). The $400 \mathrm{mg} / \mathrm{ml}$ concentration was used for all studies, except for studies involving plasma cannabinoid quantification where both 200 and $400 \mathrm{mg} / \mathrm{ml}$ concentrations were used. The final estimated concentrations of phytocannabinoids in $400 \mathrm{mg} / \mathrm{ml}$ $\mathrm{CAN}_{\mathrm{THC}}$ were as follows (in mg/ml): 113.6 THC, 5.5 CBD, and 7.2 CBN. The final concentrations in $200 \mathrm{mg} / \mathrm{ml} \mathrm{CAN}_{\mathrm{THC}}$ were as follows (in $\mathrm{mg} / \mathrm{ml}$ ): 56.8 THC, 2.75 CBD, and 3.6 CBN. The final estimated concentrations in $400 \mathrm{mg} / \mathrm{ml} \mathrm{CAN}_{\mathrm{CBD}}$ were as follows (in $\mathrm{mg} / \mathrm{ml}$ ): $3.9 \mathrm{THC}$, 237.4 CBD, 8.4 CBC, and 4.4 CBG. The final concentrations of THC and CBD in $200 \mathrm{mg} / \mathrm{ml} \mathrm{CAN}_{\mathrm{CBD}}$ were as follows (in $\mathrm{mg} / \mathrm{ml}$ ): $1.85 \mathrm{THC}, 118.7$ CBD, 4.2 CBC, and 2.2 CBG. The CB1R antagonist, AM251 (Cayman Chemical), was dissolved in dimethyl sulfoxide:Tween-80:saline (1:1:18) vehicle and administered at a dose of 0,1 , or $3 \mathrm{mg} / \mathrm{kg}$ ( $1 \mathrm{ml} / \mathrm{kg}$, i.p.). 


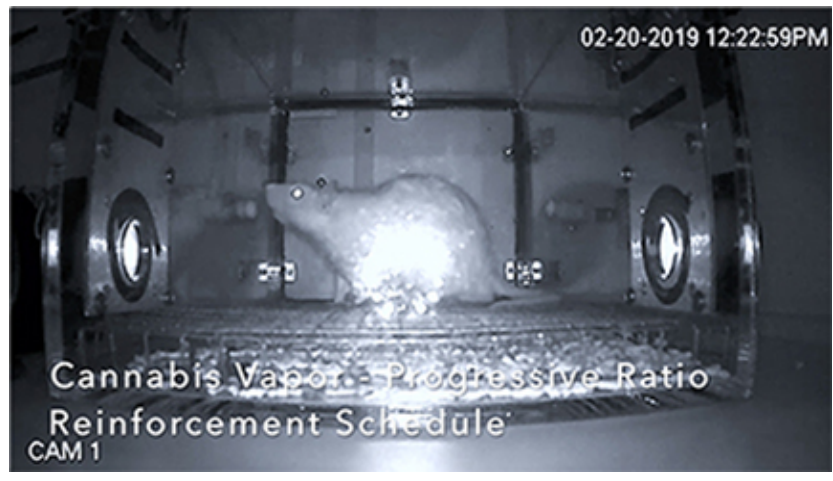

Movie 1. Movie clip of a male Sprague Dawley rat responding for $\mathrm{CAN}_{\text {THC }}$ vapor on a progressive ratio reinforcement schedule.

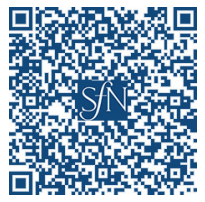

Vapor chamber apparatus. Eight $13.5 \times 9.0 \times 8.25$ inch $(\mathrm{L} \times \mathrm{W} \times \mathrm{H})$ 16.4 L vapor self-administration chambers (La Jolla Alcohol Research) were programmed using Med Associates IV software to deliver responsecontingent puffs of vapor. An uninterrupted unidirectional flow of air entered through a port in the front of the chamber, and air was removed by vacuum in the rear of the chamber lid. The air intake port pulled air through tubing connected to an air flow meter and tubing connected to a commercial e-cigarette cartridge (first generation: Protank 3 Dual Coil; $2.2 \Omega$ atomizer; Kanger Tech; second generation: SMOK Tank Baby Beast TFV8 with $0.2 \Omega \mathrm{M} 2$ atomizer, $40-60 \mathrm{~W}$ range) filled with $\mathrm{CAN}_{\mathrm{THC}}, \mathrm{CAN}_{\mathrm{CBD}}$, or VEH. Experiments involving radio telemetry, extinction, cue-induced reinstatement, CB1R antagonism, and quantification of plasma cannabinoid concentrations were conducted using first-generation vaporizers that delivered $10 \mathrm{~s}$ puffs of vapor. All other experiments were conducted using second-generation vaporizers that delivered $3 \mathrm{~s}$ puffs. These puff durations were chosen to approximate the volume of vapor produced by each vaporizer based on (1) the change in tank mass observed before versus after puff delivery, and (2) visual determination of full vapor clearance in $60 \mathrm{~s}$. Two nose-poke operanda and associated cue lights were located on the rear wall of the chamber. The cartridge was connected to a vaporizer box (La Jolla Alcohol Research), and vapor puffs were delivered through the air intake port. Chamber air was evacuated through an activated charcoal filter (Carbatrol; first generation) or in-line Whatman HEPA-Cap filters (MilliporeSigma; second generation).

Self-administration training. Rats were trained to nose-poke for $\mathrm{CAN}_{\mathrm{THC}}, \mathrm{CAN}_{\mathrm{CBD}}$, or VEH vapor puffs under a fixed ratio (FR)-1 reinforcement schedule during daily $1 \mathrm{~h}$ sessions on 11 consecutive days. Rats then progressed to an FR-2 schedule (Days 12-16) and then to an FR-4 schedule (Days 17-21). Nose-poke responses made on one (active) operandum resulted in a $3 \mathrm{~s}$ activation of the vaporizer and illumination of a cue light. The cue light remained illuminated during a $60 \mathrm{~s}$ timeout period, during which responses were not reinforced. Nose-poke responses made on the other (inactive) operandum had no programmed consequences. On the final self-administration day (Day 22), responding was reinforced under a progressive ratio (PR) schedule for $180 \mathrm{~min}$. Schedule demand increased after each vapor delivery according to the following schedule: $1,1,2,2,3,3,4,4,5,5,7,7,9,9,11,11,13,13,15,15$, $18,18,21,21,24,24$, etc. (Walker and Koob, 2007). The breakpoint was defined as the total number of vapor deliveries obtained until responding ceased for a minimum of 15 min (Movie 1).

Cannabinoid quantification. A different cohort of rats $(N=24)$ was trained to self-administer $\mathrm{CAN}_{\mathrm{THC}}$ or $\mathrm{CAN}_{\mathrm{CBD}}(200 \mathrm{or} 400 \mathrm{mg} / \mathrm{ml})$ for 12-16 consecutive days on an FR-1 reinforcement schedule, and immediately following a single $1 \mathrm{~h}$ self-administration session, blood samples $(\sim 100 \mu \mathrm{l})$ were collected to evaluate the relationship between the total number of vapor deliveries earned and circulating THC and CBD con- centrations. Blood was collected vial the tail vein in sterile tubes containing $10 \mathrm{ml}$ of ethylenediaminetetraacetic acid, centrifuged at $4^{\circ} \mathrm{C}$ at $4000 \times g$ for $15 \mathrm{~min}$, and stored at $-20^{\circ} \mathrm{C}$. THC and CBD concentrations in plasma were quantified immediately after the session as described previously (Britch et al., 2017; Greene et al., 2018).

A subset of rats from the FR/PR experiments $(N=21)$ were killed $24 \mathrm{~h}$ after their final self-administration session. Quantification of THC and CBD in brain tissue was performed as previously described (Baglot et al., under review). Briefly, frozen brain tissue was weighed and then manually homogenized (with a glass rod) in borosilicate glass culture tubes containing $2 \mathrm{ml}$ of acetonitrile with $1 \mathrm{ng}$ of THC-d3 and CBD-d3. Samples were then sonicated for $30 \mathrm{~min}$ in an ice bath and incubated overnight at $-20^{\circ} \mathrm{C}$ to precipitate proteins. The following day samples were centrifuged at $1500 \times g$ to remove particulates. The supernatant from each sample was transferred to a new glass tube and evaporated under nitrogen, the tube was then washed once with $350 \mu \mathrm{l}$ of acetonitrile (to recapture any lipids adhering to the glass wall), and the acetonitrile was dried under nitrogen gas again. After completely drying, the samples were resuspended in $200 \mu \mathrm{l}$ of 1:1 methanol-water and stored at $-80^{\circ} \mathrm{C}$ until analysis by liquid chromatography mass spectrometry. Quantification of these molecules using mass spectrometry was performed using an Eksigent Micro LC200 coupled with an AB Sciex QTRAP 5500 mass spectrometry as previously described (Baglot SL, Petrie GN, Aukema RJ, Hume C, Zhuo R, Cole M, Parker LA, Rho J, Borgland SL, McLaughlin RJ, Brechenmacher L, Hill MN, unpublished observations). The data were acquired in positive electrospray ionization and multiple reaction monitoring mode and amount of each molecule was normalized to frozen tissue weight.

$C B 1 R$ radioligand binding assay. Frozen whole brain tissue was collected from some rats $(N=12) 24 \mathrm{~h}$ after the final PR challenge to assess hippocampal CB1R binding. Tissue was homogenized in TME buffer and centrifuged to generate the crude membrane fraction. Protein concentrations were determined using the Bradford method (Bio-Rad). Membranes (10 $\mu \mathrm{g}$ protein/sample) were incubated in TME buffer with $\left[{ }^{3} \mathrm{H}\right] \mathrm{CP} 55,940(0.25,0.5,1.25$, or $2.5 \mathrm{~nm})$ in the absence or presence of AM251 $(10 \mu \mathrm{M})$ to assess total and nonspecific binding, respectively. $B_{\max }$ (maximal binding site density) and $K_{\mathrm{d}}$ (binding affinity) were calculated by nonlinear curve fitting to the single site Michaelis-Menten equation using GraphPad Prism as described previously (Lee and Hill, 2013; Berger et al., 2018).

Radio telemetry recordings. Rats $(N=8)$ were anesthetized with an isoflurane/oxygen vapor mixture (isoflurane 5\% induction, $1-3 \%$ maintenance) and a $1 \mathrm{~cm}$ midline vertical incision was made inferior to the xyphoid space. Sterile radio telemetry transmitters (Starr Life Sciences, PTD 4000) were inserted under the muscular layer and sutured in place using absorbable 4-0 silk sutures. The muscle layer was closed with 5-0 vicryl suture, and the skin was closed with non-absorbable wax-coated 4-0 silk suture. Rats received meloxicam ( $2 \mathrm{mg} / \mathrm{kg}$, s.c.) for $3 \mathrm{~d}$ for postoperative pain management. After at least $5 \mathrm{~d}$ of recovery, rats were randomly assigned to treatment groups and trained to nose-poke for $\mathrm{CAN}_{\mathrm{THC}}, \mathrm{CAN}_{\mathrm{CBD}}$, or VEH vapor on an FR-1 schedule of reinforcement. Radio telemetry transmissions indexing locomotor activity and body temperature were collected daily during $1 \mathrm{~h}$ self-administration sessions over the final $10 \mathrm{~d}$ of self-administration by Respironics ER-4000 receiver plates placed under the chambers.

Metabolic phenotyping. A subset of rats $(N=17)$ was housed individually in metabolic cages (dimensions $=\mathrm{L} 18 \times \mathrm{W} 9.5 \times \mathrm{H} 8.1$ inches; Promethion, Sable Systems) over the final $10 \mathrm{~d}$ of FR/PR self-administration training, during which feeding behavior, water intake, energy expenditure, physical activity and respiratory quotient (RQ) were monitored. Cages included a ceiling-mounted food hopper (3 mg resolution) and a water spigot connected to load cells (MM-1, Sable Systems) for food and water intake monitoring, respectively. Ad libitum access to the food hopper and water were allowed throughout the study. $X$ - and $y$-axes (horizontal plane) photoelectric beam motion detectors were positioned around each cage to assess ambulatory activity. In addition to total distance traveled, bouts of inactivity lasting $>15 \mathrm{~s}$ but $<60 \mathrm{~s}$ were tabulated and averaged for each hour. Respiratory gases were measured with an integrated fuel cell oxygen analyzer, spectrophotometric $\mathrm{CO}_{2}$ 
analyzer, and capacitive water vapor partial pressure analyzer (GA3m1, Sable Systems). The Promethion system uses a pull-mode, negative pressure system. The multichannel mass flow generator measures and controls air flow (FR8-1, Sable Systems). The incurrent flow rate was set at $2000 \mathrm{ml} / \mathrm{min}$. Water vapor was continuously measured and its dilution effect on $\mathrm{O}_{2}$ and $\mathrm{CO}_{2}$ was compensated for mathematically in the analysis (Lighton and Turner, 2008). RQ was calculated as the ratio of $\mathrm{CO}_{2}$ production to $\mathrm{O}_{2}$ consumption. Energy expenditure (i.e., the number of calories burned) was calculated using the Weir equation: $\mathrm{Kcal} / \mathrm{h}=60 \times$ $\left(0.003941 \times \mathrm{VO}_{2}+0.001106 \times \mathrm{VCO}_{2} ;\right.$ Weir, 1949). Data were acquired using MetaScreen v2.2.8, the raw data obtained were processed using ExpeData v1.8.2 (Sable Systems), and Macros 10 and 13 were used for data organization and transformation. Each day, rats were weighed, transferred to individual holding cages, and transported to the vapor self-administration system between 11:00 and 14:00. Daily values are averaged for active and inactive phases excluding the period encompassing transportation and self-administration training.

CB1R antagonism. Rats $(N=16)$ were trained to self-administer vaporized $\mathrm{CAN}_{\mathrm{THC}}$ or $\mathrm{CAN}_{\mathrm{CBD}}(400 \mathrm{mg} / \mathrm{ml})$ under an FR-1 schedule over 26 daily sessions. Rats received mock intraperitoneal injections on the $2 \mathrm{~d}$ before testing the effects of systemic CB1R antagonism on training Days 16, 21, and 26. One hour before testing, rats received AM251 (1 or 3 $\mathrm{mg} / \mathrm{kg}$, i.p.) or $\mathrm{VEH}$ using a counterbalanced within-subjects design. Additional training sessions were conducted between test sessions to re-establish stable responding. All data were converted to a percentage change score relative to the previous mock injection day.

Elevated plus maze test. The elevated plus maze (EPM) apparatus consisted of a raised Plexiglas platform (28.5 inches high) with two open exposed arms and two darker enclosed arms of equal length (21.5 inches/ arm; Med Associates). The floors were made of clear Plexiglas and the walls of both closed arms were black. Twenty-four hours after their final FR-1 self-administration session, rats $(N=37)$ were individually placed in the center of the maze and allowed to freely explore the maze for $5 \mathrm{~min}$. All tests were run in dim lighting $(\sim 10$ lux $)$, and behaviors were recorded with Noldus EthoVision XT behavioral tracking software. The number of entries and percentage time spent in the open and closed arms, and distance traveled in the open arms of the EPM were compared across groups. The frequency of risk assessment behaviors (i.e., head-dips, stretch-attend postures, and rearing) was also scored manually by trained research assistants blinded to treatment conditions as described previously (Henricks et al., 2017; Berger et al., 2018).

Extinction training and cue-induced reinstatement. Rats $(N=35)$ were trained to self-administer $\mathrm{CAN}_{\mathrm{THC}}, \mathrm{CAN}_{\mathrm{CBD}}$, or VEH under an FR-1 schedule over 19 daily sessions. Rats then underwent daily $1 \mathrm{~h}$ extinction training sessions during which nose-poke responses had no programmed consequences. Extinction training continued until rats reached the extinction criterion (i.e., $\geq 7$ extinction training sessions with $\geq 50 \%$ decrease in active nose-poke responses during the final 2 sessions). Rats were then tested for cue-induced reinstatement of extinguished drugseeking behavior. During the $1 \mathrm{~h}$ test session, active nose-poke responses resulted in cue light presentations without vapor delivery.

Experimental design and statistical analyses. Studies described herein were conducted as separate experiments using different cohorts of rats. Data pertaining to schedules of reinforcement, CB1R binding, tissue cannabinoid concentration, and metabolic phenotyping were collected in the same cohort using second-generation vaporizers. Data pertaining to extinction, cue-induced reinstatement, radio telemetry, and anxietylike behavior were collected in the same cohort using first generation vaporizers. Data pertaining to plasma cannabinoid concentration and CB1R antagonism were each collected in separate cohorts using first generation vaporizers. Vapor deliveries, active and inactive responses, trials to extinction, nose-poke discrimination, body weight, withinsession locomotor activity, food intake, water intake, lounge time, locomotor activity, energy expenditure, RQ, and EPM data were compared across groups using one-way or mixed factorial ANOVA with treatment group $\left(\mathrm{CAN}_{\mathrm{THC}}, \mathrm{CAN}_{\mathrm{CBD}}, \mathrm{VEH}\right)$ as the between-subjects factor and time (day, reinforcement schedule, $15 \mathrm{~min}$ bin, light/dark phase) as the within-subjects factor. Nose-poke discrimination was calculated based on a formula used by Spencer et al. (2018): nose-poke discrimination index $=($ active nose-pokes - inactive nose-pokes) $/$ (active nose-pokes + inactive nose-pokes), where 0 indicated no discrimination between active and inactive operanda, 1 indicated complete preference for the active operandum, and -1 indicated complete preference for inactive operandum. A discrimination index of $\geq 0.33$ is equivalent to $2: 1$ activeinactive nose-pokes. Effects of AM251 were analyzed using separate repeated-measures one-way ANOVAs. Significant effects were further probed using Tukey or Bonferroni post hoc tests. Vapor delivery and plasma cannabinoid concentrations were correlated using Pearson's correlation coefficient $(r)$. Alpha was set at 0.05 . Effect sizes are reported as $\eta_{\mathrm{P}}^{2}$.

\section{Results}

\section{THC-rich cannabis vapor supports stable rates} of self-administration

A mixed-factorial ANOVA conducted with reinforcement schedule as the within-subjects factor (averaged over all FR days for each schedule) revealed main effects of treatment $\left(F_{(2,27)}=22.20\right.$, $\left.p<0.0001, \eta_{\mathrm{P}}^{2}=0.62\right)$ and schedule $\left(F_{(2,54)}=48.37, p<0.0001\right.$, $\left.\eta_{\mathrm{P}}^{2}=0.62\right)$ on active responding, as well as a significant treatment $\times$ schedule interaction $\left(F_{(4,54)}=9.36, p<0.0001, \eta_{\mathrm{P}}^{2}=\right.$ 0.41 ; Fig. $1 C$, colored symbols). Tukey's post hoc tests indicated that $\mathrm{CAN}_{\mathrm{THC}}$ elicited more active responses than $\mathrm{CAN}_{\mathrm{CBD}}$ on FR-1 $(p=0.02)$, FR-2 $(p<0.0001)$, and FR-4 $(p<0.0001)$ schedules, and more active responses than VEH on FR-2 ( $p=$ $0.0008)$ and FR-4 $(p<0.0001)$ schedules. A mixed-factorial ANOVA also revealed a main effect of treatment on inactive responding $\left(F_{(2,27)}=6.49, p=0.005, \eta_{\mathrm{P}}^{2}=0.32\right)$, but no effect of schedule $\left(F_{(2,54)}=2.79, p=0.07, \eta_{\mathrm{P}}^{2}=0.09\right)$ or treatment $\times$ schedule interaction $\left(F_{(4,54)}=1.39, p=0.25, \eta_{\mathrm{P}}^{2}=0.09\right.$; Fig. $1 C$, open symbols). Tukey's post hoc tests indicated that $\mathrm{CAN}_{\mathrm{CBD}}$ elicited fewer inactive responses than $\mathrm{CAN}_{\mathrm{THC}}(p=0.02)$ and VEH $(p=0.01)$, regardless of reinforcement schedule.

The majority of active responding occurred during the first 15 min of the session under each reinforcement schedule (main effect of bin: $F_{(3,81)}=48.1-86.6, p$ values $<0.0001, \eta_{\mathrm{P}}^{2}=0.64-$ $0.76)$. Significant treatment $\times$ bin interactions were observed for each reinforcement schedule $\left(F_{(6,81)}=5.82-9.05, p\right.$ values $<$ $\left.0.0001, \eta_{\mathrm{P}}^{2}=0.30-0.40\right)$, and Tukey's post hoc tests indicated that $\mathrm{CAN}_{\mathrm{THC}}$ elicited more active responses than $\mathrm{CAN}_{\mathrm{CBD}}$ during the first, second, and fourth bins (all $p$ values $\leq 0.02$ ) and elicited more active responses than $\mathrm{VEH}$ and $\mathrm{CAN}_{\mathrm{CBD}}$ during each bin under FR-2 and FR-4 schedules (all $p$ values $\leq 0.03$ ). Conversely, $\mathrm{CAN}_{\mathrm{CBD}}$ elicited fewer active responses than VEH during the first $15 \mathrm{~min}$ bin under each reinforcement schedule (all $p$ values $\leq$ $0.04)$. There were also main effects of treatment $\left(F_{(2,27)}=4.84-\right.$ $5.58, p$ values $\left.\leq 0.02, \eta_{\mathrm{P}}^{2}=0.26-0.29\right)$ and $\operatorname{bin}\left(F_{(3,81)}=17.6-\right.$ 26.4, $p$ values $\left.<0.0001, \eta_{\mathrm{P}}^{2}=0.39-0.49\right)$ on the number of inactive responses made, as well as significant treatment $\times$ bin interactions for each reinforcement schedule $\left(F_{(6,81)}=6.26-\right.$ 9.47, $p$ values $\left.\leq 0.0001, \eta_{\mathrm{P}}^{2}=0.32-0.41\right)$. Tukey's post hoc tests revealed significant differences in inactive responding during the first 15 min bin, with $\mathrm{VEH}>\mathrm{CAN}_{\mathrm{THC}}>\mathrm{CAN}_{\mathrm{CBD}}$ (all $p$ values $\leq$ 0.02). During the second $15 \mathrm{~min}$ bin under the FR-4 schedule, $\mathrm{CAN}_{\mathrm{THC}}$ elicited significantly more inactive responses than $\mathrm{CAN}_{\mathrm{CBD}}(p=0.01)$ and $\mathrm{VEH}(p=0.04)$, but no differences were observed between $\mathrm{CAN}_{\mathrm{CBD}}$ and $\mathrm{VEH}$ for this bin or any other bin.

Stable rates of vapor delivery were achieved under each reinforcement schedule, as indicated by a lack of effect of day over the final $3 \mathrm{~d}$ under each schedule (Fig. 1D). A mixed-factorial ANOVA revealed main effects of treatment $\left(F_{(2,27)}=18.99, p<\right.$ $\left.0.0001, \eta_{\mathrm{P}}^{2}=0.58\right)$ and schedule $\left(F_{(2,54)}=19.01, p<0.0001\right.$, $\left.\eta_{\mathrm{P}}^{2}=0.41\right)$ on the number of vapor deliveries earned, as well as a significant treatment $\times$ schedule interaction $\left(F_{(4,54)}=4.83, p=\right.$ 
A

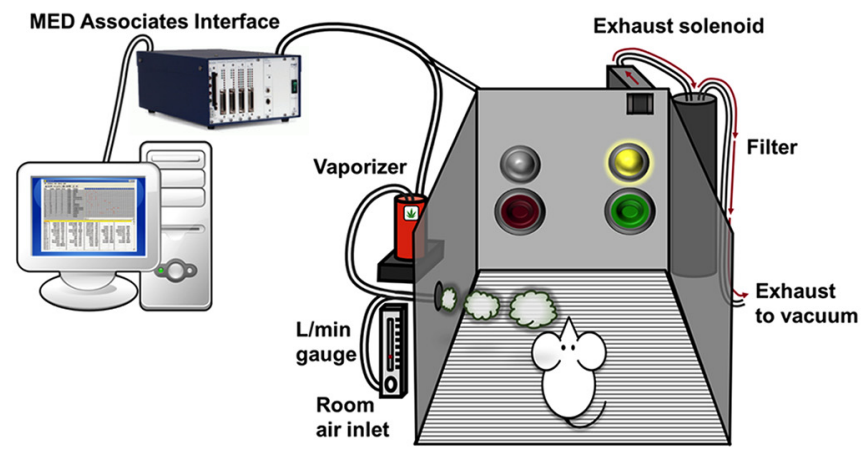

B

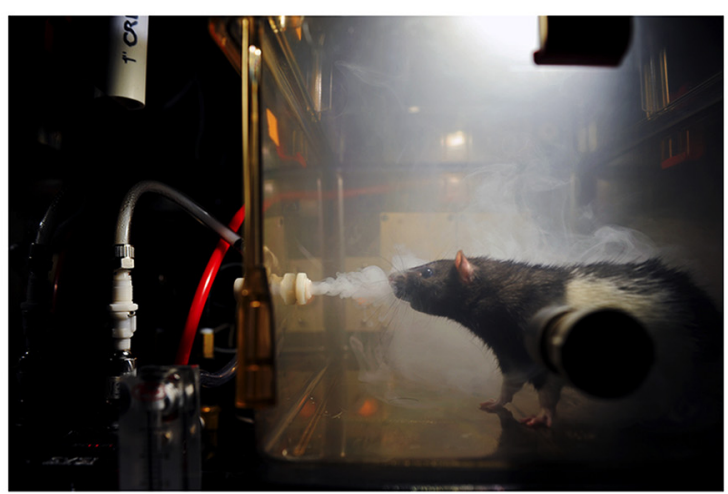

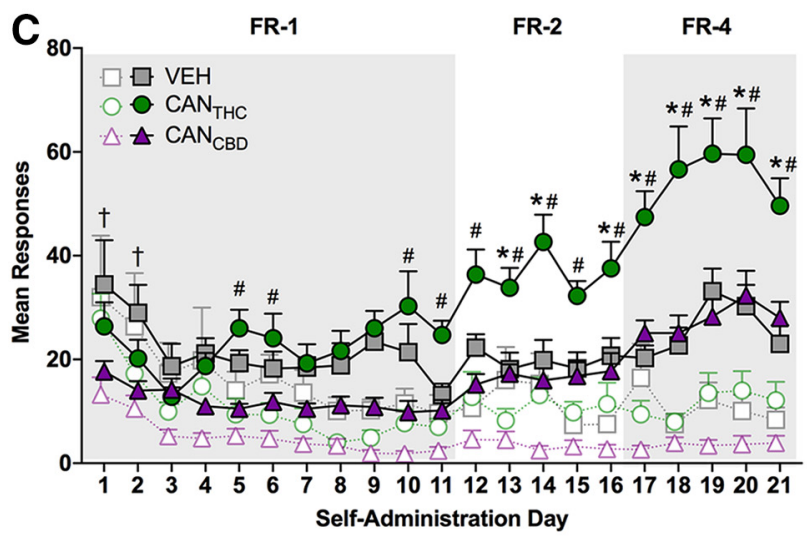
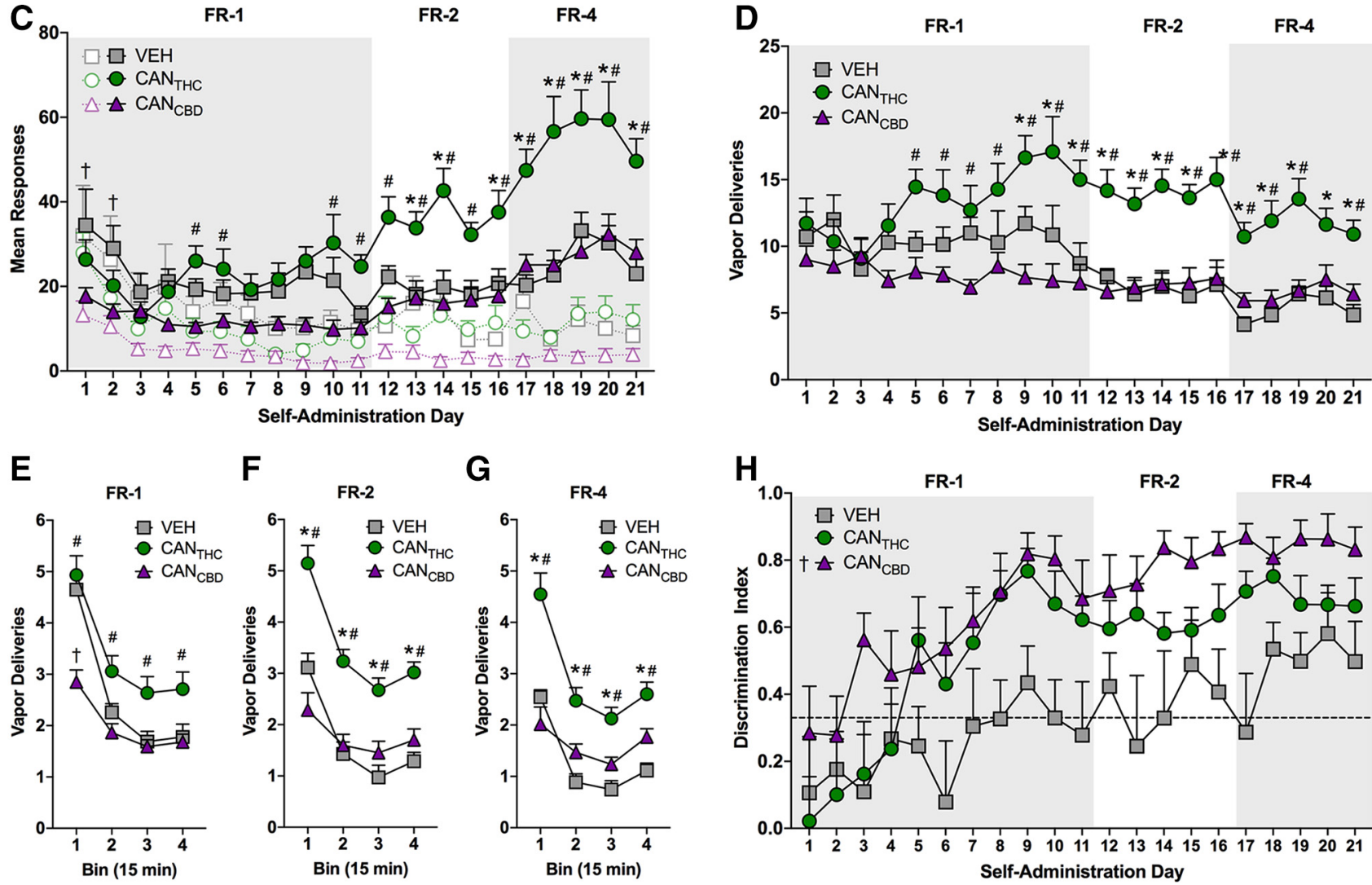

Figure 1. Cannabis vapor supports stable rates of active responding in male rats. $\boldsymbol{A}$, Schematic illustration of the vapor self-administration apparatus (adapted from Fuchs et al., 2018), and (B) real-life depiction of a Long-Evans rat responding for cannabis vapor (not from the current experiments). C, Mean active (colored symbols) and inactive (open symbols) nose-poke responding for vapor containing high concentrations of $\mathrm{CAN}_{T H C^{\prime}} \mathrm{CAN}_{\mathrm{CBD}}$, or VEH across increasing fixed ratio schedules of reinforcement. $D$, Mean number of $\mathrm{CAN}_{T H C^{\prime}} \mathrm{CAN}_{\mathrm{CBD}}$, or VEH vapor deliveries earned across increasing fixed ratio schedules of reinforcement. $\boldsymbol{E}-\boldsymbol{G}$, Mean number of vapor deliveries earned organized by 15 min bins within (E) FR-1, (F) FR-2, and (G) FR-4 schedules of reinforcement. $\boldsymbol{H}$, Nose-poke operanda discrimination index for $\mathrm{CAN}_{T H C} \mathrm{CAN}_{\mathrm{CBD}}$, and VEH vapor across increasing fixed schedules of reinforcement. The dotted line represents a discrimination index of 0.33 , which indicates a 2:1 rate of active-inactive nose-poke responding. $n=7-12 /$ group, $p \leq 0.05$. ${ }^{*}$ Significant differences between CAN $_{\text {THC }}$ and VEH groups. \#Significant differences between CAN THC $_{\text {and }}$ $\mathrm{CAN}_{\mathrm{CBD}}$ groups. †Denotes significant differences between $\mathrm{CAN}_{\mathrm{CBD}}$ and VEH groups.

$0.002, \eta_{\mathrm{P}}^{2}=0.26$; Fig. $1 D$, colored symbols). $\mathrm{CAN}_{\mathrm{THC}}$ elicited more vapor deliveries than $\mathrm{CAN}_{\mathrm{CBD}}$ on FR-1, FR-2, and FR-4 schedules, and more vapor deliveries than VEH on FR-2 and FR-4 schedules (Tukey: all $p$ values $<0.0001)$. There were also main effects of treatment $\left(F_{(2,27)}=8.72-22.0, p\right.$ values $<0.001$, $\left.\eta_{\mathrm{P}}^{2}=0.39-0.62\right)$ and bin $\left(F_{(3,81)}=53.6-224.7, p\right.$ values $<$ $\left.0.0001, \eta_{\mathrm{P}}^{2}=0.67-0.89\right)$, and significant treatment $\times$ bin interactions $\left(F_{(6,81)}=6.79-12.3, p\right.$ values $\left.<0.0001, \eta_{\mathrm{P}}^{2}=0.67-0.89\right)$ at each reinforcement schedule (Fig. $1 E-G$ ). Tukey's post hoc tests indicated that $\mathrm{CAN}_{\mathrm{THC}}$ elicited more vapor deliveries than $\mathrm{CAN}_{\mathrm{CBD}}$ during each bin under all reinforcement schedules (all $p$ values $\leq 0.03$ ), and elicited more vapor deliveries than VEH during each bin under FR-2 and FR-4 schedules (all $p$ values $\leq$ 0.001). $\mathrm{CAN}_{\mathrm{CBD}}$ elicited fewer vapor deliveries than VEH during for first 15 min bin under the FR-1 schedule $(p<0.0001)$.

One-sample $t$ tests revealed that the average nose-poke discrimination index was significantly $>0.33$ for $\mathrm{CAN}_{\mathrm{THC}}\left(t_{(20)}=\right.$ $4.39, p<0.001)$ and $\mathrm{CAN}_{\mathrm{CBD}}\left(t_{(20)}=8.77, p<0.001\right)$, but not for $\mathrm{VEH}$. Thus, only the cannabis vapor self-administering groups obtained active to inactive responding ratios that were $>2: 1$. A mixed-factorial ANOVA revealed main effects of treatment $\left(F_{(2,27)}=8.33, p=0.002, \eta_{\mathrm{P}}^{2}=0.38\right)$ and reinforcement schedule 

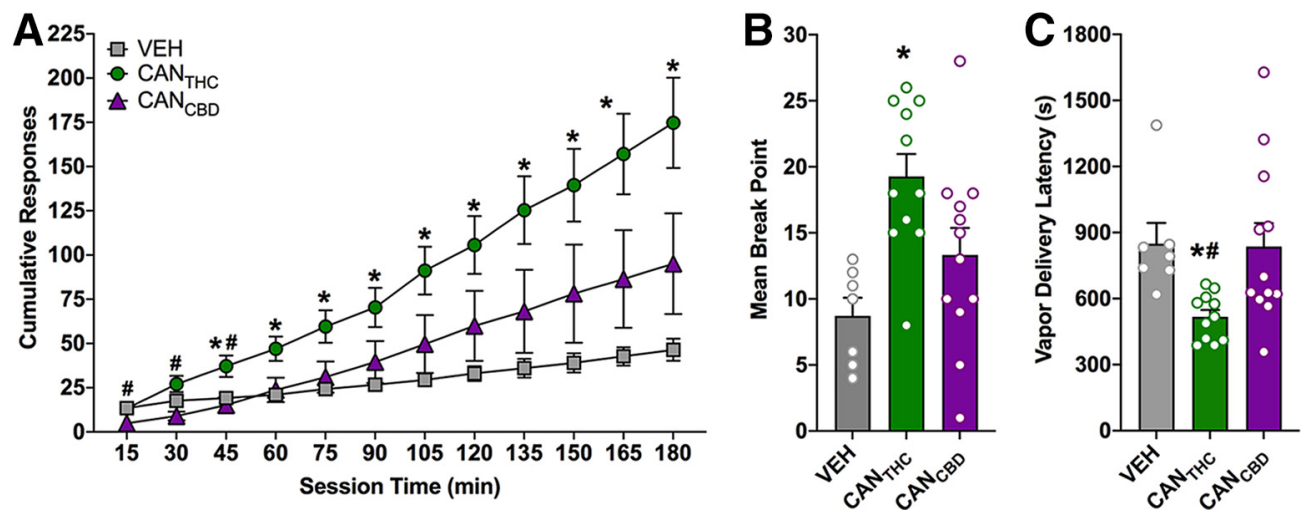

Figure 2. Vaporized delivery of THC-dominant cannabis extracts exhibits motivational properties. $A$, Mean cumulative number of active responses for $\mathrm{CAN}_{\mathrm{THC}}, \mathrm{CAN}_{\mathrm{CBD}}$, and VEH vapor during a 180 min progressive ratio challenge. Data are tallied and organized into $15 \mathrm{~min}$ bins. $\boldsymbol{B}$, Mean break points for $C \mathrm{NN}_{\mathrm{TH},} \mathrm{CAN}_{\mathrm{CBD}^{\prime}}$ and VEH vapor during the progressive ratio challenge (defined as an absence of active nose-poke responding for period of $15 \mathrm{~min}$. C, Mean latency to initiate active nose-poke responding for $\mathrm{CAN}_{\mathrm{THC}}, \mathrm{CAN}_{\mathrm{CBD}}$, or VEH vapor relative to the immediately preceding vapor delivery.

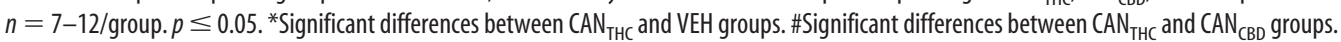

$\left(F_{(2,54)}=20.9, p<0.0001, \eta_{\mathrm{P}}^{2}=0.44\right)$ on response discrimination, but no treatment $\times$ schedule interaction $\left(F_{(4,54)}=\right.$ $0.15, p=0.96$; Fig. $1 H)$. Tukey's post hoc tests indicated that discrimination was significantly better under FR-2 and FR-4 schedules relative to FR-1 ( $p$ values < 0.05 ) and that $\mathrm{CAN}_{\mathrm{CBD}}$ elicited better discrimination for the active operandum than VEH $(p=0.001$; Fig. $1 H)$.

\section{THC-rich cannabis vapor exhibits} motivational properties

Cumulative responding under the PR schedule was analyzed using a mixedfactorial ANOVA that revealed main effects of treatment $\left(F_{(2,27)}=4.94, p=0.02\right.$, $\left.\eta_{\mathrm{P}}^{2}=0.27\right)$ and time $\left(F_{(11,297)}=32.0, p<\right.$ $\left.0.0001, \eta_{\mathrm{P}}^{2}=0.54\right)$, as well as a significant treatment $\times$ time interaction $\left(F_{(22,297)}=\right.$ $4.58, p<0.0001, \eta_{\mathrm{P}}^{2}=0.25$; Fig. $\left.2 A\right)$. Bonferroni post hoc tests correcting for multiple comparisons indicated that $\mathrm{CAN}_{\mathrm{THC}}$ produced higher cumulative responding compared with VEH from 105 to $180 \mathrm{~min}$ (all $p$ values $\leq .03$ ) and compared with CAN $_{\mathrm{CBD}}$ from 135 to $180 \mathrm{~min}$ (all $p$ values $\leq 0.02$; Fig. $2 A$ ). A one-way ANOVA indicated that $\mathrm{CAN}_{\mathrm{THC}}$ also elicited higher break points than $\operatorname{VEH}\left(F_{(2,27)}=\right.$ $7.17, p=0.001, \eta_{\mathrm{P}}^{2}=0.34$; Tukey post hoc, $p=0.001)$ and a trend for higher break points than $\mathrm{CAN}_{\mathrm{CBD}}$ (Tukey post hoc, $p=$ 0.058; Fig. 2B). Moreover, a one-way ANOVA indicated that $\mathrm{CAN}_{\mathrm{THC}}$ elicited shorter latencies to re-initiate responding following vapor deliveries compared with $\mathrm{VEH}$ and $\mathrm{CAN}_{\mathrm{CBD}}\left(F_{(2,27)}=\right.$ $5.01, p=0.01, \eta_{\mathrm{P}}^{2}=0.27$; Tukey, $p$ values $\leq 0.04$; Fig. $2 C$ ). Importantly, responding for $\mathrm{CAN}_{\mathrm{CBD}}$ was not significantly different from VEH on any endpoint measured during the PR challenge.

Cannabis vapor self-administration produces biologically relevant increases in plasma THC and CBD concentrations The number of $\mathrm{CAN}_{\mathrm{THC}}$ vapor deliveries (200 or $400 \mathrm{mg} / \mathrm{ml}$ ) measured during the $1 \mathrm{~h}$ self-administration session in a separate
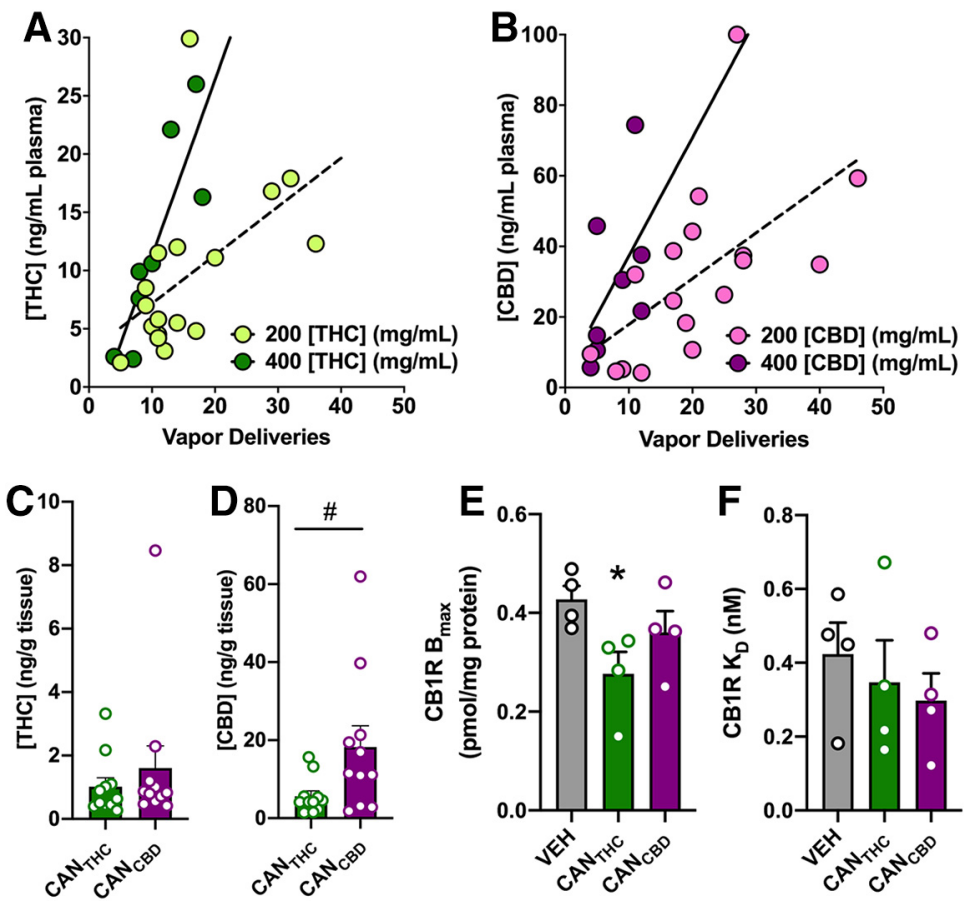

Figure 3. Cannabis vapor self-administration produces physiologically relevant cannabinoid concentrations and alterations in CB1R binding. Correlations between the number of cannabis vapor deliveries (200 or $400 \mathrm{mg} / \mathrm{ml}$ ) earned and plasma concentra-

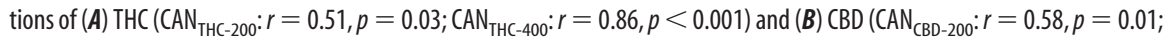
CAN $_{\text {CBD-400: }}: r=0.51, p=0.18$ at the end of the $1 \mathrm{~h}$ self-administration session $(n=8-17 /$ group). Brain tissue concentration of (C) THC and (D) CBD measured $24 \mathrm{~h}$ after the final self-administration session in rats trained to self-administer CAN $_{\text {THC }}$ or CAN $_{C B D}$ vapor $(n=$ 11/group). $\boldsymbol{E}$, Hippocampal CB1R binding site density (pmol/mg protein) and $(\boldsymbol{F})$ CB1R binding affinity (nM) in rats trained to selfadminister $\mathrm{CAN}_{\mathrm{THC}^{\prime}} \mathrm{CAN}_{\mathrm{CBD}}$, or VEH. Tissue was analyzed $24 \mathrm{~h}$ after the final self-administration session. $n=4 /$ group. $p \leq 0.05$. ${ }^{*}$ Significant differences between $C A N_{T H C}$ and VEH groups. \#Significant differences between $C A N_{T H C}$ and $C A N_{C B D}$ groups.

cohort of rats positively correlated with the concentration of THC measured in plasma immediately post-session $\left(\mathrm{CAN}_{\mathrm{THC}-200}\right.$ : $r=0.51, p=0.03$; $\mathrm{CAN}_{\mathrm{THC}-400}: r=0.86, p<0.001$; Fig. $\left.3 A\right)$. A similar relationship was observed with the number of $\mathrm{CAN}_{\mathrm{CBD}}$ vapor deliveries and the plasma concentration of CBD immediately post-session $\left(\mathrm{CAN}_{\mathrm{CBD}-200}: r=0.58, p=0.01 \mathrm{CAN}_{\mathrm{CBD}-400}\right.$ : $r=0.51, p=0.18$; Fig. 3B). Brain tissue concentrations of THC and CBD were measured $24 \mathrm{~h}$ after the PR test session from Experiment 1. Independent samples $t$ tests revealed that brain THC concentrations were not significantly different between $\mathrm{CAN}_{\mathrm{THC}}$ and $\mathrm{CAN}_{\mathrm{CBD}}$ groups $\left(t_{(20)}=0.77, p=0.45, \eta^{2}=0.03\right.$; 


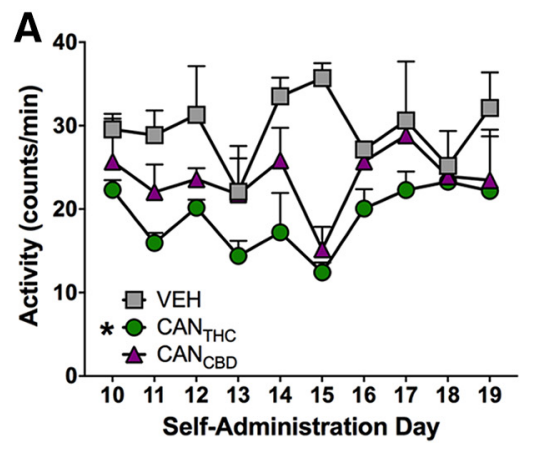

B
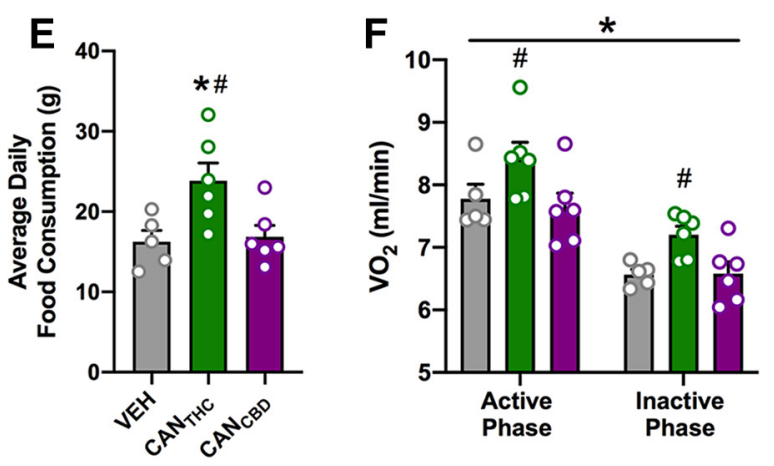
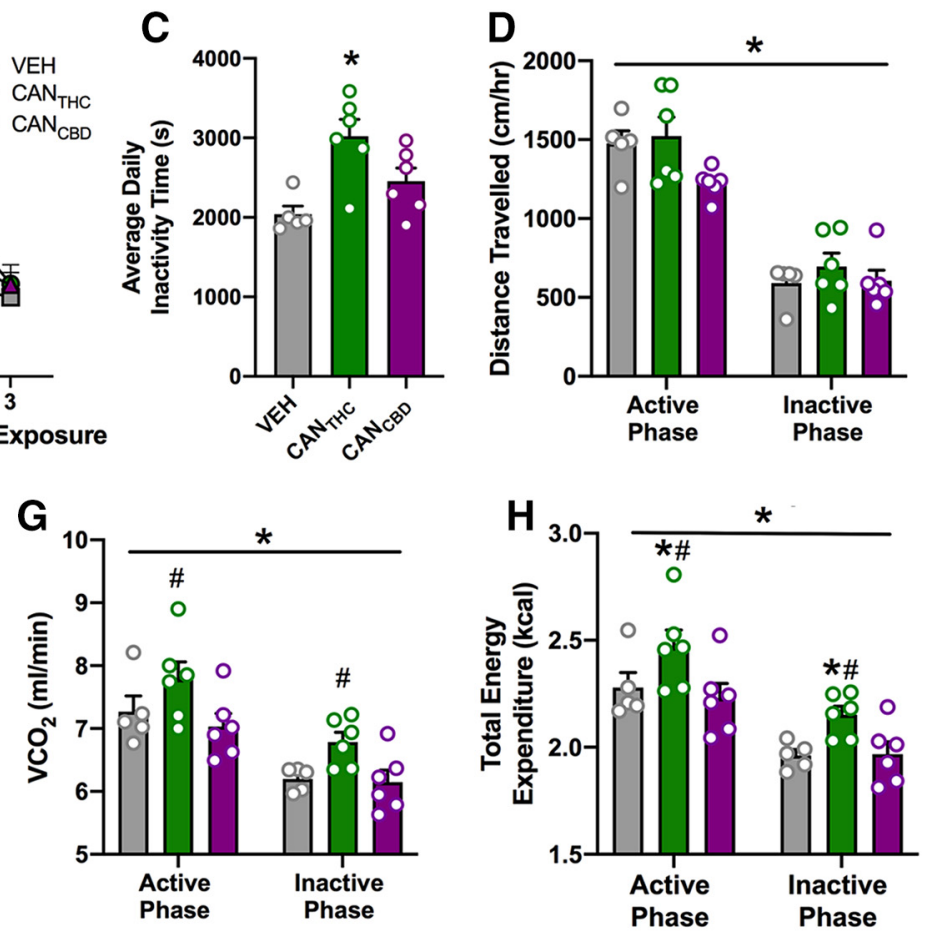

Figure 4. Self-administration of THC-rich cannabis vapor produces locomotor and metabolic alterations. $A$, Radio telemetry recordings of within-session locomotor activity (counts/ $\mathrm{min}$ ) over the final $10 \mathrm{~d}$ of self-administration in a subset of $\mathrm{CAN}_{\mathrm{TH},} \mathrm{CAN}_{\mathrm{CBD}}$, and VEH self-administering rats ( $n=2-3 /$ group). $\boldsymbol{B}$, Home cage activity measured as total time spent inactive during the $3 \mathrm{~h}$ immediately following $\mathrm{CAN}_{\mathrm{TH},}, \mathrm{CAN}_{\mathrm{CBD}}$, or VEH vapor self-administration. $C$, Total daily inactivity time in $\mathrm{CAN}_{\mathrm{THC}}, \mathrm{CAN}_{\mathrm{CBD}}$, and VEH vapor self-administering rats. $D$, Mean daily distance traveled in the home cage during the active and inactive phases in $\mathrm{CAN}_{\mathrm{TH}}, \mathrm{CAN}_{\mathrm{CBD}}$, or VEH vapor self-administering rats. E, Mean daily food consumption (grams) in $\mathrm{CAN}_{\mathrm{THC}}, \mathrm{CAN}_{\mathrm{CBD}}$, or VEH vapor self-administering rats. $\boldsymbol{F}$, Mean oxygen consumption $\left(\mathrm{VO}_{2}\right)$ and $(\boldsymbol{G})$ mean carbon dioxide consumption $\left(\mathrm{VCO}_{2}\right)$ during the active and inactive phase in $\mathrm{CAN}_{\mathrm{TH},}, \mathrm{CAN}_{\mathrm{CBD}}$, and VEH self-administering rats. $\boldsymbol{H}$, Mean energy expenditure $(\mathrm{kcal} / \mathrm{h})$ during active and inactive phases of rats trained to self-administer $\mathrm{CAN}_{\mathrm{THC}}, \mathrm{CAN}_{\mathrm{CBD}}$, or $\mathrm{VEH}$ vapor. All values are presented as averages over the final $10 \mathrm{~d}$ of self-administration training. $n=5-6 /$ group. $p \leq 0.05$. ${ }^{*}$ Significant differences between CAN $_{\text {THC }}$ and VEH groups. \#Significant differences between $\mathrm{CAN}_{\mathrm{THC}}$ and $\mathrm{CAN}_{\mathrm{CBD}}$ groups.

Fig. 3C). However, brain tissue concentrations of $\mathrm{CBD}$ were higher in the $\mathrm{CAN}_{\mathrm{CBD}}$ group compared with the $\mathrm{CAN}_{\mathrm{THC}}$ group $\left(t_{(20)}=2.24, p=0.04, \eta^{2}=0.20\right.$; Fig. $\left.3 D\right)$.

\section{$\mathrm{CAN}_{\mathrm{THC}}$ self-administration alters hippocampal CB1 receptor binding}

$\mathrm{CB} 1 \mathrm{R}$ radioligand binding assays were conducted on hippocampal tissue taken from the same brains from Experiment 1 (i.e., $24 \mathrm{~h}$ after the final PR session). Planned $t$ test comparisons between $\mathrm{CAN}_{\mathrm{THC}}$ and VEH groups revealed that $\mathrm{CAN}_{\mathrm{THC}}$ selfadministration significantly reduced $\mathrm{CB} 1 \mathrm{R}$ maximal binding site density $\left(B_{\max } ; t_{(6)}=2.90, p=0.03, \eta^{2}=0.58\right.$; Fig. $\left.3 E\right)$ without altering CB1R binding affinity $\left(K_{\mathrm{D}} ; t_{(6)}=0.53, p=0.61, \eta^{2}=\right.$ 0.05; Fig. $3 F$ ) compared with VEH, whereas $\mathrm{CAN}_{\mathrm{CBD}}$ did not significantly alter CB1R binding site density $\left(t_{(6)}=1.31, p=0.24\right.$, $\eta^{2}=0.22$; Fig. $\left.3 E\right)$ or binding affinity $\left(t_{(6)}=1.12, p=0.31, \eta^{2}=\right.$ 0.17 ; Fig. $3 F$ ) when measured $24 \mathrm{~h}$ after the final vapor selfadministration session.

$\mathrm{CAN}_{\mathrm{THC}}$ vapor self-administration alters physical activity and daily food intake

Radio telemetry recordings were taken over the final $10 \mathrm{~d}$ of FR-1 self-administration (D10-19) using a separate cohort of rats. A mixed-factorial ANOVA revealed a main effect of treatment $\left(F_{(2,5)}=5.97, p=0.047, \eta_{\mathrm{P}}^{2}=0.70\right)$, with $\mathrm{CAN}_{\mathrm{THC}}$ significantly reducing within-session locomotor activity relative to $\mathrm{VEH}$ (Tukey, $p<0.05$; Fig. $4 A)$. There was no effect of day $\left(F_{(9,45)}=\right.$ 1.64, $p=0.13, \eta_{\mathrm{P}}^{2}=0.25$ ) or treatment $\times$ day interaction $\left(F_{(18,45)}=1.09, p=0.39, \eta_{\mathrm{P}}^{2}=0.30\right)$. The number of vapor deliveries negatively correlated with locomotor activity on Days $13,16$, and 18 ( $r$ values $=0.73-98$; $p$ values $<0.05)$.

Metabolic phenotyping of a subset of rats from Experiment 1 was conducted over the final $10 \mathrm{~d}$ of self-administration. When time spent inactive was measured daily during the first $3 \mathrm{~h}$ postvapor exposure, a mixed-factorial ANOVA revealed main effects of treatment $\left(F_{(2,14)}=10.2, p=0.002, \eta_{\mathrm{P}}^{2}=0.59\right)$ and time $\left(F_{(2,28)}=51.2, p<0.0001, \eta_{\mathrm{P}}^{2}=0.79\right)$, but no significant interaction $\left(F_{(4,28)}=1.37, p=0.27, \eta_{\mathrm{P}}^{2}=0.16\right)$. Tukey's post hoc tests indicated that $\mathrm{CAN}_{\mathrm{THC}}$ increased inactivity relative to $\mathrm{CAN}_{\mathrm{CBD}}$ and VEH ( $p$ values $<0.05$; Fig. $4 B$ ). When cumulative daily inactivity time was calculated and averaged over the final $10 \mathrm{~d}$, a one-way ANOVA revealed a main effect of treatment $\left(F_{(2,14)}=\right.$ $\left.8.0, p=0.005, \eta_{\mathrm{P}}^{2}=0.53\right)$, with $\mathrm{CAN}_{\mathrm{THC}}$ self-administration resulting in more daily inactivity time compared with $\mathrm{VEH}$ (Tukey, $p<0.05$; Fig. $4 C$ ). As expected, there was a main effect of light/dark phase on the average distance traveled per day $\left(F_{(1,14)}=166, p<0.0001, \eta_{\mathrm{P}}^{2}=0.92\right)$, but no effect of treatment $\left(F_{(2,14)}=2.79, p=0.10, \eta_{\mathrm{P}}^{2}=0.28\right)$ or treatment $\times$ phase interaction $\left(F_{(2,14)}=1.82, p=0.20, \eta_{\mathrm{P}}^{2}=0.21\right.$; Fig. $\left.4 D\right)$. A one-way ANOVA indicated a main effect of treatment on total daily food intake $\left(F_{(2,14)}=5.73, p=0.02, \eta_{\mathrm{P}}^{2}=0.42\right)$ with $\mathrm{CAN}_{\mathrm{THC}}$ increasing mean food intake over the last $10 \mathrm{~d}$ of training relative to $\mathrm{VEH}$ and $\operatorname{CAN}_{\mathrm{CBD}}$ (Tukey, both $p<0.03$; Fig. $4 E$ ). A one-way ANOVA also revealed a main effect of day on weight gain $\left(F_{(13,169)}=80.8\right.$, $\left.p<0.0001, \eta_{\mathrm{P}}^{2}=0.86\right)$, but there was no effect of treatment $\left.F_{(2,13)}=1.11, p=0.36, \eta_{\mathrm{P}}^{2}=0.15\right)$ or treatment $\times$ day interaction $\left(F_{(26,169)}=0.88, p=0.64, \eta_{\mathrm{P}}^{2}=0.12\right)$, which indicates that 
neither $\mathrm{CAN}_{\mathrm{THC}}$ nor $\mathrm{CAN}_{\mathrm{CBD}}$ significantly altered bodyweight gain. Pearson correlation analyses examining associations between hourly/daily food intake and average vapor deliveries earned over the last $10 \mathrm{~d}$ did not reveal any significant relationships between these variables. $\mathrm{O}_{2}$ consumption $\left(\mathrm{VO}_{2}\right)$ and $\mathrm{CO}_{2}$ consumption $\left(\mathrm{VCO}_{2}\right)$ differed according to phase $\left(F_{(1,14)}=\right.$ 98.8 $-140.00, p$ values $\left.<0.001, \eta_{\mathrm{P}}^{2}=0.88-0.91\right)$ and treatment $\left(F_{(1,14)}=4.04-4.49, p\right.$ values $\left.=0.03, \eta_{\mathrm{P}}^{2}=0.22-0.24\right)$, with $\mathrm{CAN}_{\mathrm{THC}}$ producing higher $\mathrm{VO}_{2}$ and $\mathrm{VCO}_{2}$ values compared with $\mathrm{CAN}_{\mathrm{CBD}}$ when averaged over the final $10 \mathrm{~d}$ (Tukey: $p$ values $<$ 0.05; Fig. $4 F, G$ ). A mixed-factorial ANOVA assessing energy expenditure also revealed main effects of phase $\left(F_{(1,14)}=179.00\right.$, $\left.p<0.001, \eta_{\mathrm{P}}^{2}=0.93\right)$ and treatment $\left(F_{(2,14)}=5.17, p=0.021\right.$, $\left.\eta_{\mathrm{P}}^{2}=0.42\right)$, but no phase $\times$ treatment interaction $\left(F_{(2,14)}=0.28\right.$, $p=0.76$; Fig. $4 H$ ). Tukey's post hoc tests revealed that $\mathrm{CAN}_{\mathrm{THC}}$ increased energy expenditure compared with both VEH and $\mathrm{CAN}_{\mathrm{CBD}}$ (both $p<0.05$; Fig. $4 H$ ). Total food and water intake were higher during the active versus inactive phase $\left(F_{(1,14)}=\right.$ $25.0-166, p$ values $\left.<0.001, \eta_{\mathrm{P}}^{2}=0.64-0.92\right)$ but did not differ according to treatment, and there were no effects of phase or treatment on RQs.

\section{The reinforcing effects of vaporized $\mathrm{CAN}_{\mathrm{THC}}$ require $\mathrm{CB} 1$ receptor stimulation}

Systemic CB1R antagonism differentially impaired the reinforcing effects of vaporized $\mathrm{CAN}_{\mathrm{THC}}$ and $\mathrm{CAN}_{\mathrm{CBD}}$. Baseline active responding and vapor deliveries were not statistically different between conditions, and VEH treatment did not alter these measures relative to mock injection. Repeated-measures ANOVAs revealed a main effect of AM251 treatment on active responding $\left(F_{(2,14)}=6.05, p=0.01, \eta_{\mathrm{P}}^{2}=0.46\right)$ and vapor deliveries earned $\left(F_{(2,14)}=7.44, p=0.01, \eta_{\mathrm{P}}^{2}=0.52\right)$, with the 1 and $3 \mathrm{mg} / \mathrm{kg}$ dose of AM251 decreasing $\mathrm{CAN}_{\mathrm{THC}^{-}}$-reinforced active responses (Tukey, $p$ values $=0.04$ and 0.02 , respectively) and vapor deliveries (Tukey, $p$ values $=0.03$ and 0.01 , respectively) relative to baseline (Fig. $5 A, B$ ). In contrast, there was no effect of AM251 treatment on $\mathrm{CAN}_{\mathrm{CBD}}$-reinforced active responding $\left(F_{(2,14)}=\right.$ $1.17, p=0.34, \eta_{\mathrm{P}}^{2}=0.14$; Fig. $\left.5 C\right)$ or the number of $\mathrm{CAN}_{\mathrm{CBD}}$ vapor deliveries earned $\left(F_{(2,14)}=2.11, p=0.16, \eta_{\mathrm{P}}^{2}=0.23\right.$; Fig. $5 D)$. AM251 treatment did not significantly alter inactive responding for $\mathrm{CAN}_{\mathrm{THC}}\left(F_{(2,14)}=0.05, p=0.95\right)$ or $\mathrm{CAN}_{\mathrm{CBD}}$ $\left(F_{(2,14)}=1.98, p=0.18\right)$.

\section{Acute withdrawal from cannabis vapor does not elicit anxiety-like behavior}

Behaviors in the EPM were measured $24 \mathrm{~h}$ after the final vapor self-administration session, and one-way ANOVAs indicated that neither $\mathrm{CAN}_{\mathrm{THC}}$ nor $\mathrm{CAN}_{\mathrm{CBD}}$ history altered the percentage of time spent in the open arms of the $\operatorname{EPM}\left(F_{(2,34)}=0.53\right.$, $\left.p=0.48, \eta_{\mathrm{P}}^{2}=0.03\right)$, the number of open arm entries made $\left(F_{(2,34)}=1.12, p=0.34, \eta_{\mathrm{P}}^{2}=0.06\right)$, the number of rearing events $\left(F_{(2,34)}=0.12, p=0.89, \eta_{\mathrm{P}}^{2}=0.007\right)$, or the frequency of stretchattend postures $\left(F_{(2,34)}=2.90, p=0.07, \eta_{\mathrm{P}}^{2}=0.15\right.$; for descriptive statistics, see Table 2).

\section{Removal of cannabis vapor reinforcement elicits an extinction burst}

Rates of vapor self-administration did not differ between groups on the final self-administration day $\left(F_{(2,32)}=3.1, p=0.06, \eta_{\mathrm{P}}^{2}=\right.$ 0.16; Fig. 6A). A mixed factorial ANOVA examining effects of treatment on active responding on the last day of selfadministration relative to the first day of extinction revealed a
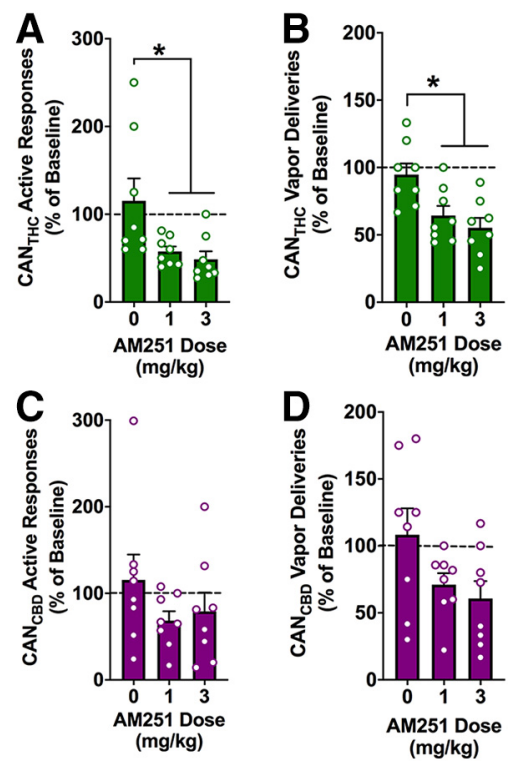

Figure 5. The reinforcing effects of vaporized $C A N_{T H C}$ require $C B 1$ receptor stimulation Mean $(\boldsymbol{A})$ active nose-poke responses for $\mathrm{CAN}_{\mathrm{THC}}$ and $(\boldsymbol{B}) \mathrm{CAN}_{\mathrm{THC}}$ vapor deliveries following systemic administration of the CB1R antagonist $A M 251$ (0, 1, or $3 \mathrm{mg} / \mathrm{kg}$, i.p.). Mean (C) active nose-poke responses for $C_{C N_{C D D}}$ and $(\boldsymbol{D}) \mathrm{CAN}_{\mathrm{CBD}}$ vapor deliveries following systemic administration of the $C B 1$ Rantagonist $A M 251$ (0, 1, or $3 \mathrm{mg} / \mathrm{kg}$, i.p.). Data are depicted as a percentage of baseline from the preceding mock injection day. $p \leq 0.05$. *Significant differences between CAN $_{\text {THC }}$ and VEH groups.

Table 2. EPM behavior following acute forced abstinence from vapor

\begin{tabular}{llllll}
\hline $\begin{array}{l}\text { Treatment } \\
\text { group }\end{array}$ & $n$ & $\begin{array}{l}\text { Open arm } \\
\text { time, } \%\end{array}$ & $\begin{array}{l}\text { Open arm } \\
\text { entries }\end{array}$ & $\begin{array}{l}\text { Rearing } \\
\text { events }\end{array}$ & $\begin{array}{l}\text { Stretch-attend } \\
\text { postures }\end{array}$ \\
\hline VEH & 11 & $16.32 \pm 4.86$ & $3.09 \pm 0.73$ & $22.45 \pm 1.20$ & $10.93 \pm 1.03$ \\
CAN $_{\text {THC }}$ & 13 & $11.04 \pm 2.18$ & $2.00 \pm 0.35$ & $22.55 \pm 1.22$ & $8.47 \pm 0.71$ \\
CAN $_{\text {CBD }}$ & 13 & $12.80 \pm 4.19$ & $3.07 \pm 0.67$ & $23.32 \pm 1.62$ & $8.15 \pm 0.85$ \\
\hline
\end{tabular}

Values for EPM measures represent mean \pm SEM.

main effect of day $\left(F_{(1,32)}=27.1, p<0.0001, \eta_{\mathrm{P}}^{2}=0.46\right)$ and a significant treatment $\times$ day interaction $\left(F_{(2,32)}=3.47, p=0.04\right.$, $\left.\eta_{\mathrm{P}}^{2}=0.17\right)$. Bonferroni post hoc tests indicated that removal of $\mathrm{CAN}_{\mathrm{THC}}$ or $\mathrm{CAN}_{\mathrm{CBD}}$ increased active responding on the first extinction day relative to the last self-administration day (both $p<0.005)$, whereas removal of VEH did not alter active responses (Fig. 6A). A mixed factorial ANOVA conducted over the first seven extinction days revealed a main effect of day $\left(F_{(6,192)}=\right.$ 7.40, $\left.p<0.0001, \eta_{\mathrm{P}}^{2}=0.33\right)$ and a significant treatment $\times$ day interaction $\left(F_{(12,192)}=1.95, p=0.03, \eta_{\mathrm{P}}^{2}=0.11\right)$. Bonferroni post hoc tests indicated that removal of $\mathrm{CAN}_{\mathrm{THC}}$ elicited more active responses than $\mathrm{VEH}$ on extinction Days $1-3$ (all $p$ values $\leq 0.03$ ). There was also a significant treatment $X$ day interaction for inactive responding $\left(F_{(12,192)}=3.13, p=0.0004, \eta_{\mathrm{P}}^{2}=0.16\right)$, such that removal of $\mathrm{CAN}_{\mathrm{CBD}}$ elicited fewer inactive responses than removal of VEH on Day 6 (Bonferroni: $p=0.044$ ) and fewer than removal of $\mathrm{CAN}_{\mathrm{THC}}$ on Day 4 (Bonferroni, $p=0.004$; Fig. $6 A$ ). Interestingly, removal of $\mathrm{CAN}_{\mathrm{CBD}}$ increased the number of sessions rats needed to reach the extinction criterion compared with $\mathrm{CAN}_{\mathrm{THC}}\left(F_{(2,32)}=4.09, p=0.03, \eta_{\mathrm{P}}^{2}=0.20\right.$, Tukey post hoc, $p=$ 0.03; Fig. 6B).

\section{$\mathrm{CAN}_{\mathrm{THC}^{-}}$or $\mathrm{CAN}_{\mathrm{CBD}}$-paired stimuli elicit reinstatement of cannabis vapor-seeking behavior}

A mixed factorial ANOVA examining vapor cue-induced active responding revealed that response-contingent presentation of ei- 

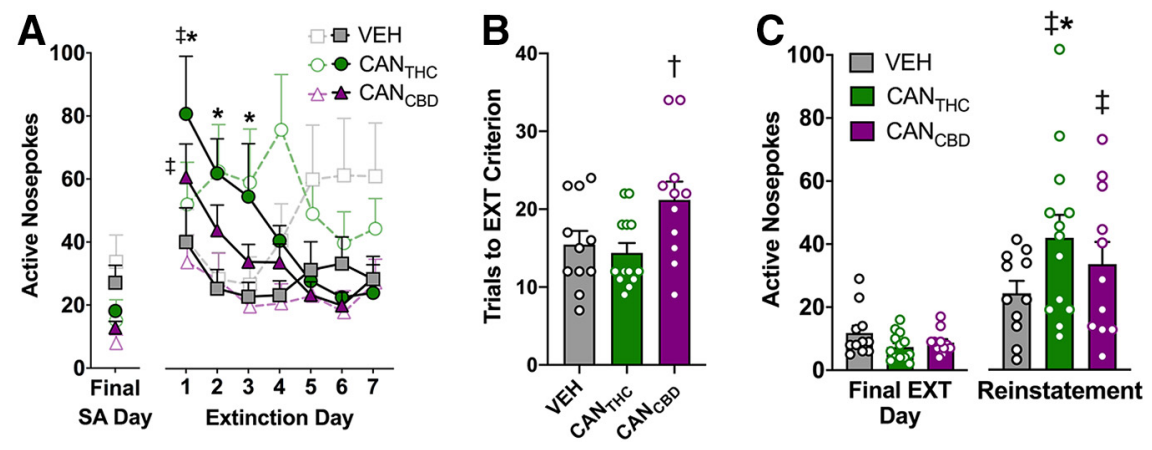

Figure 6. Cannabis vapor supports conditioned drug seeking in the absence of drug availability or in the presence of drugrelated cues. $A$, Active (colored symbols) and inactive (open symbols) responding for $\mathrm{CAN}_{\mathrm{TH}}, \mathrm{CAN}_{\mathrm{CB}}$, or VEH vapor on the final day of self-administration training (left) and during the first $7 \mathrm{~d}$ of extinction training (right). $\boldsymbol{B}$, Number of trials required to meet extinction criterion (i.e., $\geq 50 \%$ decrease in active nose-poke responses relative to the final self-administration day during the final two extinction sessions). $C$, Number of nose-poke responses made on the active operanda for $\mathrm{CAN}_{\mathrm{TH}} \mathrm{CAN}_{\mathrm{CBD}}$, or VEH vapor on the final day of extinction (left) and during a cue-induced reinstatement test (left). $n=11-13 /$ group. $p \leq 0.05$. $\neq$ Significant difference in responding relative to the final day of $(\boldsymbol{A})$ self-administration or $(\boldsymbol{C})$ extinction training. *Significant differences between $\mathrm{CAN}_{\mathrm{THC}}$ and VEH groups. "Significant differences between $\mathrm{CAN}_{\mathrm{CBD}}$ and VEH groups.

ther the $\mathrm{CAN}_{\mathrm{THC}^{-}}$or the $\mathrm{CAN}_{\mathrm{CBD}}$-paired (but not the $\mathrm{VEH}$ paired) light cue increased active responses at test relative to the last extinction training day (interaction: $F_{(2,32)}=3.14, p=0.05$, $\eta_{\mathrm{P}}^{2}=0.18$; Bonferroni post hoc, $p$ values $<0.05$; Fig. $\left.6 C\right)$. Response-contingent cue presentation also altered inactive responding over the final extinction and reinstatement test days $\left(F_{(2,32)}=3.34, p=0.05, \eta_{\mathrm{P}}^{2}=0.17\right)$, with $\mathrm{CAN}_{\mathrm{CBD}}$ rats making fewer inactive responses than $\mathrm{VEH}$ rats regardless of cue presentation $(p=0.04)$. Planned comparison $t$ tests examining effects of $\mathrm{CAN}_{\mathrm{THC}}$ and $\mathrm{CAN}_{\mathrm{CBD}}$ on cue-induced active responding relative to $\mathrm{VEH}$ indicated that the $\mathrm{CAN}_{\mathrm{THC}}$-paired cue elicited more active responses than the VEH-paired cue $\left(t_{(22)}=2.11, p=0.05\right.$, $\eta_{\mathrm{P}}^{2}=0.16$; Fig. $6 C$ ). There were no differences between $\mathrm{CAN}_{\mathrm{CBD}}$ and VEH for cue-induced active responding $\left(t_{(20)}=1.14, p=\right.$ 0.27 ), and no significant differences in inactive responding between $\mathrm{CAN}_{\mathrm{THC}}$ and $\operatorname{VEH}\left(t_{(22)}=0.13, p=0.90\right)$ or $\mathrm{CAN}_{\mathrm{CBD}}$ and $\mathrm{VEH}\left(t_{(20)}=1.42, p=0.17\right)$ groups.

\section{Discussion}

Obstacles in establishing a model of cannabis use that closely mimics the human experience have limited our ability to study the neural mechanisms and impact of cannabis use (Melis et al., 2017; McLaughlin, 2018). In the current study, we present evidence supporting the feasibility of a novel preclinical model of cannabis self-administration that employs response-contingent delivery of vaporized cannabis extracts. Our findings indicate that THC-dominant cannabis vapor $\left(\mathrm{CAN}_{\mathrm{THC}}\right)$ has reinforcing properties. Despite variability in rates of self-administration, both cannabis self-administering groups exhibited stable rates of responding and demonstrated robust discrimination between active and inactive operanda. Although all rats show increased responding early in the session, responding for $\mathrm{CAN}_{\mathrm{THC}}$ was significantly higher than $\mathrm{VEH}$ and $\mathrm{CAN}_{\mathrm{CBD}}$ during this time, which is consistent with a preserved loading dose phenomenon. Importantly, active responding was highest for $\mathrm{CAN}_{\mathrm{THC}}$, and only the $\mathrm{CAN}_{\mathrm{THC}}$ self-administering group defended the number of vapor deliveries earned under more demanding schedules of reinforcement. Finally, $\mathrm{CAN}_{\mathrm{THC}}$ elicited higher break points under the PR reinforcement schedule and supported the acquisition of conditioned motivational effects by an initially neutral environmental stimulus. These findings support previous efforts demonstrating the feasibility of vapor self-

\section{ately after the session. Self-administered} $\mathrm{CAN}_{\mathrm{THC}}$ reliably reduced locomotor activity during the session and increased the duration of inactivity in the metabolic chambers during the first $2 \mathrm{~h}$ following the self-administration session, which is congruent with recent studies using passive THC vapor delivery (Nguyen et al., 2016). $\mathrm{CAN}_{\mathrm{THC}}$ also increased daily food intake and energy expenditure. These data mirror observations of increased caloric intake and energy expenditure of chronic cannabis users (Smit and Crespo, 2001; Rodondi et al., 2006; Le Strat and Le Foll, 2011; Meier et al., 2019). Moreover, CB1R binding was significantly reduced in the hippocampus $24 \mathrm{~h}$ after the final self-administration in $\mathrm{CAN}_{\mathrm{THC}}$ rats compared with $\mathrm{VEH}$ rats, which is in line with studies in human cannabis users (Ceccarini et al., 2015) and rodents repeatedly injected with THC (Romero et al., 1997; Silva et al., 2015; Farquhar et al., 2019; Kruse et al., 2019). Notably, biologically relevant THC and CBD concentrations were observed in brain tissue $24 \mathrm{~h}$ after the final selfadministration session, which may account for the lack of abstinence-induced anxiety-like behavior observed in this study. Brain CBD concentrations were higher than brain THC concentrations, probably because of the long half-life of CBD (i.e., 24-48 h; Millar et al., 2018). THC tissue concentration was low but detectable, and similar in both $\mathrm{CAN}_{\mathrm{THC}}$ and $\mathrm{CAN}_{\mathrm{CBD}}$ rats. CBD inhibits the cytochrome P450 family of liver enzymes that are responsible for THC metabolism (Zendulka et al., 2016). Thus, comparable brain THC concentrations following $\mathrm{CAN}_{\mathrm{THC}}$ and $\mathrm{CAN}_{\mathrm{CBD}}$ regimens might reflect greater $\mathrm{CBD}$-mediated inhibition of THC metabolism in the $\mathrm{CAN}_{\mathrm{CBD}}$ group. This possibility will need to be systematically evaluated in future studies.

The vapor self-administration procedure likely facilitated volitional cannabis exposure. It has been well documented for other drugs of abuse that control over drug administration profoundly alters the subjective effects of drug intake, as well as the associated neurochemical responses (Stefański et al., 1999, 2007; Donny et al., 2000). Following passive intravenous THC administration, humans report aversive effects that are most often caused by the dose and rate of infusion (Carbuto et al., 2012). These factors likely also influence the feasibility of intravenous self-administration in rodents. Notably, we used cannabis extracts containing THC, CBD, and other naturally-occurring phytocannabinoids, which could also mitigate the aversive effects of high-dose THC exposure (Russo and Guy, 2006). Notably, CBD facilitates intra- 
venous THC self-administration in rodents (Spencer et al., 2018; but see Wakeford et al., 2017) and offsets some of the pharmacological and behavioral effects of THC in humans (Morgan et al., 2010) and rodents (Englund et al., 2013). Furthermore, a passive $\mathrm{THC}+\mathrm{CBD}$ vapor pre-exposure regimen facilitates the acquisition of intravenous THC + CBD self-administration (Spencer et al., 2018). However, it is unknown whether CBD is required for self-administration of vaporized THC. It should be noted that difficulties in establishing intravenous THC self-administration may be due more to differences in dosing, procedures, and species, rather than the presence of particular phytocannabinoids per se (for review, see Panlilio et al., 2010). Thus, future studies should test both whole cannabis extracts, as well as isolated constituents in combination to evaluate interactions between THC, $\mathrm{CBD}$, and other phytocannabinoids.

THC and CBD concentrations vary widely across commercially available cannabis products. As such, it will be important to study the extent to which modifying cannabinoid constituent concentrations alters the propensity for self-administration. In the current study, we compared responding for two different cannabis extracts and observed key differences between their effects. First, $\mathrm{CAN}_{\mathrm{THC}}$, but not $\mathrm{CAN}_{\mathrm{CBD}}$, elicited significant reinforcing effects as indicated by augmented operant responding upon increases in schedule demand. Second, $\mathrm{CAN}_{\mathrm{THC}}$ had greater motivational effects as indicated by higher breakpoints and a reduced latency to initiate responding following vapor delivery compared with $\mathrm{CAN}_{\mathrm{CBD}}$. Although both $\mathrm{CAN}_{\mathrm{THC}}$ and $\mathrm{CAN}_{\mathrm{CBD}}$ self-administration regimens were sufficient to increase drug seeking upon the removal of the reinforcer (i.e., extinction) or in the presence of vapor-associated cues (i.e., reinstatement) relative to responding during the last self-administration session and relative to the absence of cues, respectively, only the $\mathrm{CAN}_{\mathrm{THC}}$ regimen elicited response rates above that of the $\mathrm{VEH}$ group. Thus, $\mathrm{CAN}_{\mathrm{THC}}$ vapor has greater reinforcing properties and stronger conditioned motivational effects than $\mathrm{CAN}_{\mathrm{CBD}}$ and VEH vapor.

Interestingly, the $\mathrm{CAN}_{\mathrm{CBD}}$ regimen produced the strongest discrimination between active and inactive operanda despite reduced rates of responding. Furthermore, $\mathrm{CAN}_{\mathrm{CBD}}$ elicited drug-seeking behavior that was more resistant to extinction, as indicated by a larger number of sessions required to reach extinction criterion relative to $\mathrm{CAN}_{\mathrm{THC}}$. Detectable brain concentrations of THC and a CBD-mediated decrease in the aversive properties of THC likely reconcile these findings with studies indicating a lack of CBD-mediated reinforcement (Haney et al., 2016; Viudez-Martínez et al., 2019). Additionally, CBD enhances the efficacy of THC to produce discriminative stimulus effects in rhesus monkeys (McMahon, 2016). Thus, the high concentration of $\mathrm{CBD}$ in the $\mathrm{CAN}_{\mathrm{CBD}}$ extract may have augmented the discriminative effects of THC, resulting in more persistent, inflexible drug seeking. If this is the case, then high-CBD cannabis products that also contain THC may still have abuse liability concerns akin to more THC-dominant products. More rigorous interrogation into effects of vaporized CBD will undoubtedly provide insight into potential reinforcing properties of CBD in the presence and absence of THC (Javadi-Paydar et al., 2018, 2019).

The reinforcing properties of cannabis vapor self-administration require $\mathrm{CB} 1 \mathrm{R}$ stimulation, as our data indicate that rates of $\mathrm{CAN}_{\mathrm{THC}^{-}}$(but not $\mathrm{CAN}_{\mathrm{CBD}^{-}}$) reinforced responding were decreased following acute AM251 administration. This is consistent with studies in nonhuman primates indicating that CB1R blockade selectively attenuates THC reinforcement without altering cocaine- or food-reinforced responding (Tanda et al., 2000;
Schindler et al., 2016). AM251 administration may have also induced a state of precipitated withdrawal that could have influenced responding. Although we did not find evidence for spontaneous withdrawal in the EPM, precipitated withdrawal has been more reliably observed in THC-treated rodents (Cook et al., 1998; Lichtman et al., 2001) and nonhuman primates (Stewart and McMahon, 2010). Thus, future studies should examine whether CB1R antagonism causes precipitated withdrawal in this model.

Although the use of whole-plant cannabis extracts more accurately models human consumption, this approach does introduce additional sources of variability. For instance, although concentrations of some primary phytocannabinoids were provided in the NIDA certificate of analysis, we were only provided with details on a subset of phytocannabinoids and did not perform additional onsite analytics. We also used two different vaporizers/vapor delivery regimens and multiple batches of extracts for these experiments. Thus, the vapor quantity administered per puff and the concentration of phytocannabinoids present in these extracts may have varied slightly between experiments. However, despite these added sources of variability, the data from these experiments are remarkably consistent in demonstrating the reinforcing effects of vaporized cannabis delivery. Nevertheless, more rigorous investigation into cannabis vapor dosing parameters and kinetics is needed to better inform future studies using this approach.

Altogether, findings from the present study strongly support the utility of a response-contingent vapor delivery protocol as a means to model cannabis use and further examine the neurobiological mechanisms underlying cannabis-seeking behavior. Ultimately, this model will permit finer interrogation of the effects of cannabis on the brain and behavior and help to identify causal factors that increase the susceptibility for developing cannabis use disorders.

\section{References}

Berger AL, Henricks AM, Lugo JM, Wright HR, Warrick CR, Sticht MA, Morena M, Bonilla I, Laredo SA, Craft RM, Parsons LH, Grandes PR, Hillard CJ, Hill MN, McLaughlin RJ (2018) The lateral habenula directs coping styles under conditions of stress via recruitment of the endocannabinoid system. Biol Psychiatry 84:611-623.

Britch SC, Wiley JL, Yu Z, Clowers BH, Craft RM (2017) Cannabidiol- $\Delta$ 9tetrahydrocannabinol interactions on acute pain and locomotor activity. Drug Alcohol Depend 175:187-197.

Carbuto M, Sewell RA, Williams A, Forselius-Bielen K, Braley G, Elander J, Pittman B, Schnakenberg A, Bhakta S, Perry E, Ranganathan M, D’Souza DC, Yale THC Study Group (2012) The safety of studies with intravenous $\Delta^{9}$-tetrahydrocannabinol in humans, with case histories. Psychopharmacology 219:885-896.

Ceccarini J, Kuepper R, Kemels D, van Os J, Henquet C, Van Laere K (2015) $\left[{ }^{18} \mathrm{~F}\right] \mathrm{mk}-9470$ pet measurement of cannabinoid $\mathrm{cb} 1$ receptor availability in chronic cannabis users. Addict Biol 20:357-367.

Cook SA, Lowe JA, Martin BR (1998) CB1 receptor antagonist precipitates withdrawal in mice exposed to Delta9-tetrahydrocannabinol. J Pharmacol Exp Ther 285:1150-1156.

Donny EC, Caggiula AR, Rose C, Jacobs KS, Mielke MM, Sved AF (2000) Differential effects of response-contingent and response-independent nicotine in rats. Eur J Pharmacol 402:231-240.

Englund A, Morrison PD, Nottage J, Hague D, Kane F, Bonaccorso S, Stone JM, Reichenberg A, Brenneisen R, Holt D, Feilding A, Walker L, Murray RM, Kapur S (2013) Cannabidiol inhibits thc-elicited paranoid symptoms and hippocampal-dependent memory impairment. J Psychopharmacol 27:19-27.

Farquhar CE, Breivogel CS, Gamage TF, Gay EA, Thomas BF, Craft RM, Wiley JL (2019) Sex, THC, and hormones: effects on density and sensitivity of cb1 cannabinoid receptors in rats. Drug Alcohol Depend 194:2027. 
Fisar Z (2009) Phytocannabinoids and endocannabinoids. Curr Drug Abuse Rev 2:51-75.

Fuchs RA, Higginbotham, JA, Hansen EJ (2018) Animal models of drug addiction. In: Neural mechanisms of addiction (Torregrossa M, ed), pp 3-22. London: Academic, Elsevier.

Greene NZ, Wiley JL, Yu Z, Clowers BH, Craft RM (2018) Cannabidiol modulation of antinociceptive tolerance to $\Delta^{9}$-tetrahydrocannabinol. Psychopharmacology 235:3289-3302.

Grotenhermen F (2003) Pharmacokinetics and pharmacodynamics of cannabinoids. Clin Pharmacokinet 42:327-360.

Haney M, Malcolm RJ, Babalonis S, Nuzzo PA, Cooper ZD, Bedi G, Gray KM, McRae-Clark A, Lofwall MR, Sparenborg S, Walsh SL (2016) Oral cannabidiol does not alter the subjective, reinforcing or cardiovascular effects of smoked cannabis. Neuropsychopharmacology 41:1974-1982.

Hasin DS, Keyes KM, Alderson D, Wang S, Aharonovich E, Grant BF (2008) Cannabis withdrawal in the United States: results from nesarc. J Clin Psychiatry 69:1354-1363.

Henricks AM, Berger AL, Lugo JM, Baxter-Potter LN, Bieniasz KV, Petrie G, Sticht MA, Hill MN, McLaughlin RJ (2017) Sex- and hormonedependent alterations in alcohol withdrawal-induced anxiety and corticolimbic endocannabinoid signaling. Neuropharmacology 124:121-133.

Hill AJ, Williams CM, Whalley BJ, Stephens GJ (2012) Phytocannabinoids as novel therapeutic agents in CNS disorders. Pharmacol Ther 133:79-97.

Hložek T, Uttl L, Kadeřábek L, Balíková M, Lhotková E, Horsley RR, Nováková P, Š́́chová K, Štefková K, Tylš F, Kuchař M, Páleníček T (2017) Pharmacokinetic and behavioural profile of THC, CBD, and THC +CBD combination after pulmonary, oral, and subcutaneous administration in rats and confirmation of conversion in vivo of CBD to THC. Eur Neuropsychopharmacol 27:1223-1237.

Huestis MA (2007) Human cannabinoid pharmacokinetics. Chem Biodivers 4:1770-1804.

Jaffe AB, Sharpe LG, Jaffe JH (1989) Rats self-administer sufentanil in aerosol form. Psychopharmacology 99:289-293.

Javadi-Paydar M, Nguyen JD, Kerr TM, Grant Y, Vandewater SA, Cole M, Taffe MA (2018) Effects of $\Delta 9$-thc and cannabidiol vapor inhalation in male and female rats. Psychopharmacology 235:2541-2557.

Javadi-Paydar M, Creehan KM, Kerr TM, Taffe MA (2019) Vapor inhalation of cannabidiol (CBD) in rats. Pharmacol Biochem Behav 184: 172741.

Kruse LC, Cao JK, Viray K, Stella N, Clark JJ (2019) Voluntary oral consumption of $\Delta^{9}$-tetrahydrocannabinol by adolescent rats impairs rewardpredictive cue behaviors in adulthood. Neuropsychopharmacology 44: $1406-1414$.

Laprairie RB, Bagher AM, Kelly ME, Dupré DJ, Denovan-Wright EM (2014) Type 1 cannabinoid receptor ligands display functional selectivity in a cell culture model of striatal medium spiny projection neurons. J Biol Chem 289:24845-24862.

Laprairie RB, Bagher AM, Kelly ME, Denovan-Wright EM (2015) Cannabidiol is a negative allosteric modulator of the cannabinoid $\mathrm{CB} 1$ receptor. Br J Pharmacol 172:4790-4805.

Laprairie RB, Bagher AM, Kelly ME, Denovan-Wright EM (2016) Biased type 1 cannabinoid receptor signaling influences neuronal viability in a cell culture model of huntington disease. Mol Pharmacol 89:364-375.

Lee TT, Hill MN (2013) Age of stress exposure modulates the immediate and sustained effects of repeated stress on corticolimbic cannabinoid cb1 receptor binding in male rats. Neuroscience 249:106-114.

Le Strat Y, Le Foll B (2011) Obesity and cannabis use: results from 2 representative national surveys. Am J Epidemiol 174:929-933.

Lewis MA, Russo EB, Smith KM (2018) Pharmacological foundations of cannabis chemovars. Planta Med 84:225-233.

Lichtman AH, Fisher J, Martin BR (2001) Precipitated withdrawal is reversed by $\delta^{9}$-tetrahydrocannabinol or clonidine. Pharmacol Biochem Behav 69:181-188.

Lighton JR, Turner RJ (2008) The hygric hypothesis does not hold water: abolition of discontinuous gas exchange cycles does not affect water loss in the ant Camponotus vicinus. J Exp Biol 211:563-567.

Manwell LA, Charchoglyan A, Brewer D, Matthews BA, Heipel H, Mallet PE (2014) A vapourized $\Delta^{9}$-tetrahydrocannabinol ( $\Delta^{9}$-THC) delivery system part i: development and validation of a pulmonary cannabinoid route of exposure for experimental pharmacology studies in rodents. J Pharmacol Toxicol Methods 70:120-127.
McLaughlin RJ (2018) Toward a translationally relevant preclinical model of cannabis use. Neuropsychopharmacology 43:213.

McMahon LR (2016) Enhanced discriminative stimulus effects of $\Delta^{9}$-THC in the presence of cannabidiol and 8-OH-DPAT in rhesus monkeys. Drug Alcohol Depend 165:87-93.

Meier MH, Pardini D, Beardslee J, Matthews KA (2019) Associations between cannabis use and cardiometabolic risk factors: a longitudinal study of men. Psychosom Med 81:281-288.

Melis M, Frau R, Kalivas PW, Spencer S, Chioma V, Zamberletti E, Rubino T, Parolaro D (2017) New vistas on cannabis use disorder. Neuropharmacology 124:62-72.

Millar SA, Stone NL, Yates AS, O'Sullivan SE (2018) A systematic review on the pharmacokinetics of cannabidiol in humans. Front Pharmacol 9:1365.

Morgan CJ, Freeman TP, Schafer GL, Curran HV (2010) Cannabidiol attenuates the appetitive effects of delta 9-tetrahydrocannabinol in humans smoking their chosen cannabis. Neuropsychopharmacology 35:18791885.

Nguyen JD, Aarde SM, Vandewater SA, Grant Y, Stouffer DG, Parsons LH, Cole M, Taffe MA (2016) Inhaled delivery of $\Delta^{9}$-tetrahydrocannabinol (THC) to rats by e-cigarette vapor technology. Neuropharmacology 109:112-120.

Panlilio LV, Justinova Z, Goldberg SR (2010) Animal models of cannabinoid reward. Br J Pharmacol 160:499-510.

Rodondi N, Pletcher MJ, Liu K, Hulley SB, Sidney S (2006) Marijuana use, diet, body mass index, and cardiovascular risk factors (from the CARDIA study). Am J Cardiol 98:478-484.

Romero J, Garcia-Palomero E, Castro JG, Garcia-Gil L, Ramos JA, Fernandez-Ruiz JJ (1997) Effects of chronic exposure to $\delta^{9}$-tetrahydrocannabinol on cannabinoid receptor binding and mRNA in several rat brain regions. Brain Res Mol Brain Res 46:100-108.

Russo E, Guy GW (2006) A tale of two cannabinoids: the therapeutic rationale for combining tetrahydrocannabinol and cannabidiol. Med Hypotheses 66:234-246.

Russo EB (2011) Taming THC: potential cannabis synergy and phytocannabinoid-terpenoid entourage effects. Br J Pharmacol 163:13441364.

Schindler CW, Redhi GH, Vemuri K, Makriyannis A, Le Foll B, Bergman J, Goldberg SR, Justinova Z (2016) Blockade of nicotine and cannabinoid reinforcement and relapse by a cannabinoid CB1-receptor neutral antagonist AM4113 and inverse agonist rimonabant in squirrel monkeys. Neuropsychopharmacology 41:2283-2293.

Sexton M, Cuttler C, Finnell JS, Mischley LK (2016) A cross-sectional survey of medical cannabis users: patterns of use and perceived efficacy. Cannabis Cannabinoid Res 1:131-138.

Silva L, Harte-Hargrove L, Izenwasser S, Frank A, Wade D, Dow-Edwards D (2015) Sex-specific alterations in hippocampal cannabinoid 1 receptor expression following adolescent delta-9-tetrahydrocannabinol treatment in the rat. Neurosci Lett 602:89-94.

Smit E, Crespo CJ (2001) Dietary intake and nutritional status of us adult marijuana users: results from the third national health and nutrition examination survey. Public Health Nutr 4:781-786.

Spencer S, Neuhofer D, Chioma VC, Garcia-Keller C, Schwartz DJ, Allen N, Scofield MD, Ortiz-Ithier T, Kalivas PW (2018) A model of $\Delta^{9}$ tetrahydrocannabinol self-administration and reinstatement that alters synaptic plasticity in nucleus accumbens. Biol Psychiatry 84:601-610.

Stefański R, Ladenheim B, Lee SH, Cadet JL, Goldberg SR (1999) Neuroadaptations in the dopaminergic system after active self-administration but not after passive administration of methamphetamine. Eur J Pharmacol 371:123-135.

Stefański R, Ziółkowska B, Kuśmider M, Mierzejewski P, Wyszogrodzka E, Kołomańska P, Dziedzicka-Wasylewska M, Przewłocki R, Kostowski W (2007) Active versus passive cocaine administration: differences in the neuroadaptive changes in the brain dopaminergic system. Brain Res 1157: $1-10$.

Stewart JL, McMahon LR (2010) Rimonabant-induced Delta9-tetrahydrocannabinol withdrawal in rhesus monkeys: discriminative stimulus effects and other withdrawal signs. J Pharmacol Exp Ther 334: $347-356$

Tanda G (2016) Preclinical studies on the reinforcing effects of cannabinoids: a tribute to the scientific research of Dr. Steve Goldberg. Psychopharmacology 233:1845-1866. 
Tanda G, Munzar P, Goldberg SR (2000) Self-administration behavior is maintained by the psychoactive ingredient of marijuana in squirrel monkeys. Nat Neurosci 3:1073-1074.

Vendruscolo JCM, Tunstall BJ, Carmack SA, Schmeichel BE, Lowery-Gionta EG, Cole M, George O, Vandewater SA, Taffe MA, Koob GF, Vendruscolo LF (2018) Compulsive-like sufentanil vapor self-administration in rats. Neuropsychopharmacology 43:801-809.

Viudez-Martínez A, García-Gutiérrez MS, Medrano-Relinque J, Navarrón CM, Navarrete F, Manzanares J (2019) Cannabidiol does not display drug abuse potential in mice behavior. Acta Pharmacol Sin 40:358-364.

Wakeford AGP, Wetzell BB, Pomfrey RL, Clasen MM, Taylor WW, Hempel BJ, Riley AL (2017) The effects of cannabidiol (CBD) on $\Delta^{9}$ - tetrahydrocannabinol (THC) self-administration in male and female Long-Evans rats. Exp Clin Psychopharmacol 25:242-248.

Walker BM, Koob GF (2007) The gamma-aminobutyric acid-b receptor agonist baclofen attenuates responding for ethanol in ethanol-dependent rats. Alcohol Clin Exp Res 31:11-18.

Weinhold LL, Sharpe LG, Jaffe JH (1993) Housing conditions influence acquisition of sufentanil aerosol self-administration in rats. Pharmacol Biochem Behav 44:141-144.

Weir JB (1949) New methods for calculating metabolic rate with special reference to protein metabolism. J Physiol 109:1-9.

Zendulka O, Dovrtělová G, Nosková K, Turjap M, Šulcová A, Hanuš L, Juřica J (2016) Cannabinoids and cytochrome p450 interactions. Curr Drug Metab 17:206-226. 